\title{
EXPLORANDO DINÁMICAS POBLACIONALES ANCESTRALES EN EL NORESTE PERUANO: MARCADORES UNIPARENTALES DE ADN EN LOS CHACHAPOYA

\author{
MODERNOS
}

\author{
Evelyn K. Guevara ${ }^{a}$, Jukka U. Palo ${ }^{b}$ Antti Sajantilac, Sonia Guillén ${ }^{d}$
}

\begin{abstract}
Resumen
El objetivo de este estudio es entender la historia poblacional de los chachapoya al determinar: 1) la cantidad y naturaleza de la diversidad genética en la población Chachapoya moderna y en grupos vecinos (Huancas, Jivaro, y Cajamarca), 2) afinidades genéticas entre los chachapoya y poblaciones de pool andino y amazónico, 3) si hubo una reducción drástica de la diversidad genética Chachapoya, ya que la documentación etnohistórica reporta un colapso demográfico notable en la región. Para tales fines, estudiamos la diversidad mitocondrial (HVRI y HVRII) y de cromosoma Y (23STRs) en cuatro poblaciones de la región Amazonas (Chachapoya $=276$, Jivaro $=47$, Huancas $=21, y$ Cajamarca $=34$ ). Observamos el flujo genético europeo asimétrico en la región (Chachapoya: $A D N$ mitocondrial=11\%; cromosoma $Y=43 \%$ ). Al examinar únicamente el componente nativo-americano, la población Chachapoya mostró niveles relativamente altos de diversidad genética y elevados indices Tajima's $D$ and Fu's Fs. Esto sugiere que no existieron reducciones drásticas en el tamaño poblacional en el pasado. En el contexto de transformaciones culturales en la región, la posición basal de los chachapoyas entre las poblaciones sudamericanas puede sugerir que las civilizaciones que se desarrollaron en la frontera Andes-Amazonía habrían desempeñado un rol más importante entre las sociedades del noreste andino.
\end{abstract}

Palabras clave: ADN mitocondrial, cromosoma Y, población basal, Chachapoya

\section{Abstract \\ EXPLORING ANCESTRAL POPULATION DYNAMICS IN NORTHEASTERN PERU: DNA UNIPARENTAL MARKERS IN THE MODERN CHACHAPOYA}

This study aimed to provide a better understanding of the population history of the Chachapoyas by assessing 1) the amount and nature of genetic diversity in the modern Chachapoya and their immediate neighbors (Huancas, Jivaro, and Cajamarca), 2) the genetic affinities of the Chachapoya and populations from Andean and Amazonian pools, and 3) whether a severe reduction of the genetic diversity in the Chachapoya occurred since ethnohistorical documents report a drastic population decline in the region. We studied mitochondrial (HVRI and HVRII sequences) and Y-chromosomal (23 STR loci) diversity in four populations (Chachapoya $=276$, Jivaro=47, Huancas $=21$, and Cajamarca=34) from the Amazonas region. Our findings show asymmetrical European gene flow in the region (Chachapoya: $m t D N A=11 \%$; $Y$-Chromosome $=43 \%)$. When examining the Native American component only, the Chachapoya population displayed relatively high levels of genetic diversity and large Tajima's D and Fu's $F$ s values. This suggests that no drastic reduction in

a Department of Forensic Medicine, University of Helsinki

Correo electrónico: evelyn.guevara@helsinki.fi

b Department of Forensic Medicine, University of Helsinki

Correo electrónico: jukka.palo@helsinki.fi

c Department of Forensic Medicine, University of Helsinki

Correo electrónico: antti.sajantila@helsinki.fi

d Centro Mallqui, Instituto de Bioarqueología

Correo electrónico: soniaguillen@gmail.com 
the effective population size has taken place in the past. In the context of cultural transformations in the region, the basal position of the Chachapoya amidst the South American populations may suggest that civilizations which developed along the Andes-Amazon divide played a more important role among the societies in the Northeast Andes.

Keywords: MtDNA, Y-chromosome, basal population, Chachapoya

\section{Introducción}

El territorio Chachapoya, ubicado en la frontera nororiental de las esferas de interacción de los Andes Centrales, se ha mantenido por muchos años al margen del interés de la comunidad científica. No es hasta hace pocos años atrás que existe un renovado interés, no sólo por la arqueología Chachapoyas (Church y von Hagen 2008; Koschmieder 2010; Guengerich 2015), sino, además, por el estudio de sociedades mucho más tempranas (Olivera 2012; Clasby 2014).

Durante la década pasada, la evidencia genética ha asumido un rol fundamental en la evaluación de ciertas hipótesis que emergen de la arqueología, la historia y la lingüística. La caracterización genética de las poblaciones contemporáneas de América ha probado ser de suma utilidad para reconstruir procesos de dinámica poblacional a diferente escala (Batista provincia de. 1995; Fuselli provincia de. 2003; Schmitt provincia de. 2004; Lewis provincia de. 2005; Tamm provincia de. 2007; Perego provincia de. 2010;). A pesar de la existencia de argumentos que ponen en relieve las limitaciones de un enfoque basado en el estudio de $\mathrm{ADN}$ en poblaciones modernas, ciertamente es posible usar esta perspectiva para hacer inferencias sobre fenómenos ocurridos en la historia poblacional de determinados grupos.

\section{Las poblaciones locales y su entorno}

Los Andes nororientales tienen una configuración geofísica singular que ha producido una gama variada de zonas ecológicas, desde bosques montanos y premontanos, hasta sistemas alpinos y subalpinos (Holdridge 1967). La topografía en el área Chachapoya es variable, con altitudes que van desde 1000 a más de $4000 \mathrm{msnm}$. Estos elementos, sumados a la influencia climatológica de sistemas adyacentes (v.g. cuenca Amazónica), han hecho posible crear una ecología compleja y altos niveles de biodiversidad en la región.

Este segmento de los Andes (sur de Ecuador y norte de Perú), ha permitido la formación de innumerables corredores que, sin duda, facilitaron el acceso a diversos ecosistemas y sus recursos. Las pocas barreras fisiográficas, como ha sido notado por algunos investigadores (Brunschön y Behling 2009), han permitido incluso el avance de especies vegetales de este a oeste. Otro elemento fundamental en esta parte de los Andes es que las distancias para transitar de una zona ecológica a otra son mucho más cortas que en otras latitudes, e incluso el movimiento desde la costa a la Amazonía sería mejor en términos costo-efectivo (menos días).

\section{Las fuentes arqueológicas}

La topografía y fisiografía entre el sur de Ecuador y el noreste de Perú (Fig. 1), podría haber facilitado el movimiento de los primeros grupos trashumantes desde diferentes extremos, situación que más hacia el norte o hacia el sur se dificulta. De hecho, investigaciones en sitios tempranos como la cueva Manachaqui (3650 msnm), situada en el extremo sur del territorio Chachapoyas, y con ocupaciones tempranas de 12000 y 11900 A.P. (calib.), han revelado la existencia de puntas de proyectil que se asemejan a industrias líticas del sitio El Inga en la sierra ecuatoriana y de Paiján en la costa norte del Perú (Church y von Hagen 2008), reforzando la idea de que esta es una región 


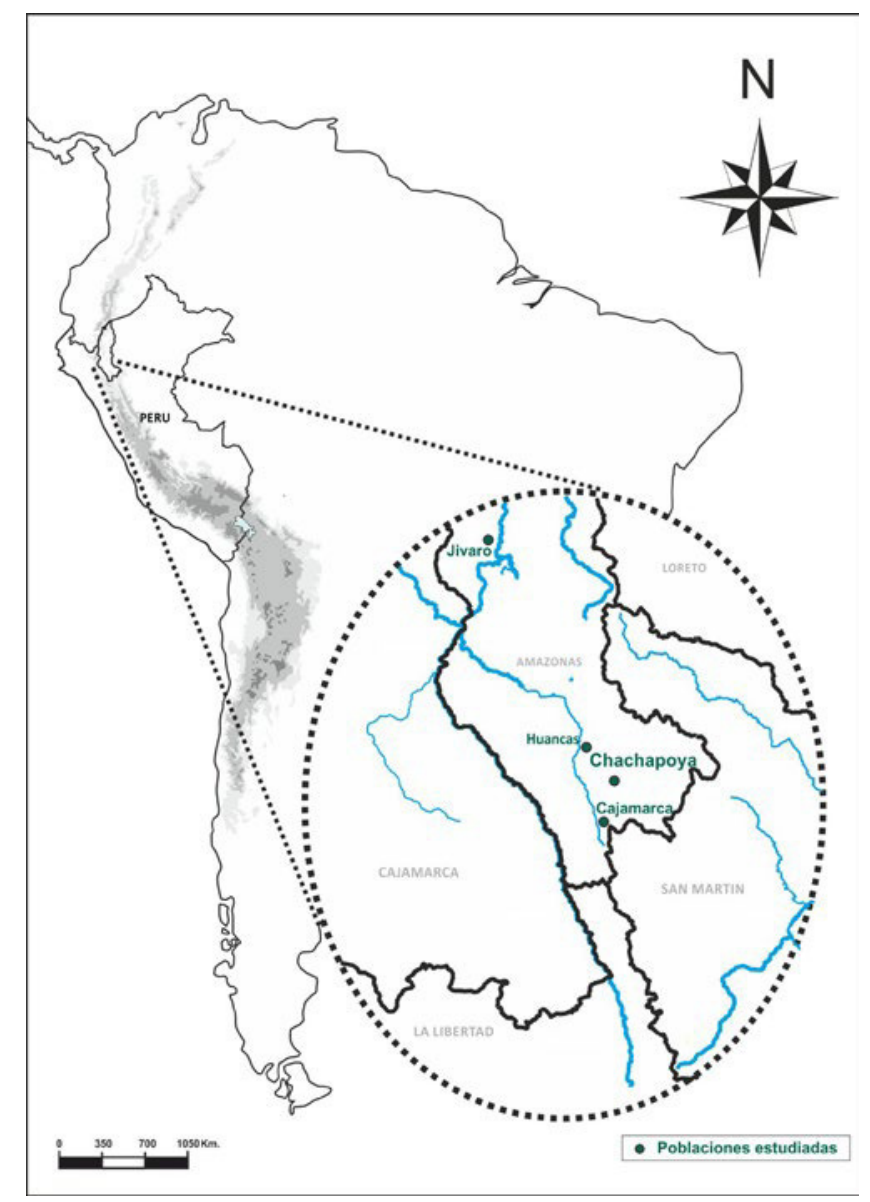

Figura 1. Mapa de Sudamérica con la ubicación de las poblaciones estudiadas.

de intenso tránsito. En esta misma línea, los autores sugieren que estas puntas de proyectil bien podrían representar la extensión sureste de una industria lítica norteña y que la gran variedad estilística además podría significar que más de un grupo trashumante usó esta cueva. Además de los trabajos en la cueva Manachaqui, hasta ahora son inexistentes en la región estudios que se hayan concentrado en las primeras ocupaciones sudamericanas y proporcionado un registro arqueológico completo. Las innumerables cuevas y abrigos rocosos tienen el potencial de cubrir ese vacío; sin embargo, debido a la naturaleza de la investigación arqueológica, debemos aguardar nuevos descubrimientos.

Los sitios con ocupación más tardía (v.g., Formativo, Período Intermedio Tardío), han aportado evidencia que también apunta a intensos contactos entre las sociedades asentadas en el bosque nuboso y otras en regiones vecinas o más alejadas (Olivera 1998; Church y von Hagen 2008; Guffroy 2008; Clasby 2014). Esto brinda sustento adicional a la importancia de esta región en la formación y transformación de sociedades del nororiente peruano.

\section{Objetivos y preguntas}

A pesar de los avances notables en la arqueología y bioarqueología chachapoya, nuestro conocimiento sobre los orígenes de estas poblaciones y sus características biogeográficas aún es limitado. 
Elementos en la iconografía chachapoya aluden a rasgos típicos del entorno amazónico, apoyando la idea de una interacción constante con poblaciones vecinas de la Amazonía. Igualmente, productos provenientes de tierras bajas tropicales encontrados en contextos arqueológicos denotan ciertos niveles de accesibilidad a una gran gama de recursos provenientes de aquellos ecosistemas (von Hagen 2002, 2004; Church y von Hagen 2008; Guengerich 2014). La frontera oeste, delimitada por el río Marañón, pareciera no haber sido una gran barrera para la comunicación entre poblaciones pertenecientes a dos áreas culturales contiguas, Chachapoyas y Cajamarca. Los artefactos de origen Cajamarca en sitios chachapoya sugieren una fuerte influencia cultural de sociedades asentadas al oeste, desde el período Intermedio Temprano (Ruiz 1972; Schjellerup 2005; Church y von Hagen 2008;). La arqueología de la región ha demostrado que el territorio Chachapoyas habría sido un área de intenso tránsito y que las sociedades formadas en el bosque nuboso eran vitales en el funcionamiento de las redes de intercambio en el noreste del Perú; sin embargo, no sabemos el impacto de estas interacciones en la estructura genética de las poblaciones locales, de haber existido alguno. Examinar la diversidad genética de las poblaciones locales y compararla con otros grupos nos va a permitir revelar vínculos entre poblaciones a nivel biológico ( $v$.g., flujo genético) y constituye uno de nuestros primeros objetivos.

Durante el Horizonte Tardío, los inka trasladaron gran parte de las poblaciones locales a otros territorios controlados por el estado, produciendo una disminución del tamaño de las poblaciones locales (Lerche 1995; Schjellerup 2005). El arribo de los conquistadores marcó igualmente un período crítico de reestructuración poblacional a nivel biológico y social. Las enfermedades, los constantes enfrentamientos bélicos y la sobreexplotación de la mano de obra local, redujeron a la población nativa de América. La evidencia histórica indica además que el colapso demográfico en el nororiente peruano fue rápido, generalmente mayor que el promedio de la sierra norte y muy similar al de las zonas costeras (Cook 2010). Tomando en cuenta estos eventos históricos, la expectativa sería observar limitada diversidad genética en las poblaciones de la región debido a una constante disminución del tamaño de las poblaciones locales en el pasado.

Con el presente enfoque, estudiando el ADN de los «descendientes chachapoyas» modernos, buscamos entender cómo los eventos históricos (v.g. llegada de los europeos a América) y/o elementos biogeográficos, han modelado la diversidad genética de estas poblaciones. La etiqueta «Chachapoyas» en este texto se refiere a los pobladores que habitan actualmente en territorio con evidencia cultural chachapoya y que forman parte de nuestra muestra. Cabe aclarar, que la capital de la región Amazonas es la ciudad de Chachapoyas, también referida en el texto.

Específicamente buscamos: 1) caracterizar la diversidad genética en la población Chachapoya moderna y en tres poblaciones vecinas, Jívaro, Huancas, y Cajamarca; 2) identificar afinidades genéticas entre los Chachapoyas y otras poblaciones de origen andino o amazónico; 3) determinar si hubo una reducción drástica de la diversidad genética en la población Chachapoya, esto último vinculado al colapso demográfico registrado en fuentes históricas (Cook 2010; Lerche 1995). Analizamos para esto la diversidad mitocondrial (HVR1 y HVR2) y de cromosoma Y (23-loci) en cuatro poblaciones de la región Amazonas (Fig. 1): Chachapoya $(N=276)$, Jívaro $(N=47)$, Huancas $(N=21)$ y Cajamarca $(N=34)$.

\section{Materiales y métodos}

\subsection{Las poblaciones estudiadas}

Chachapoya. Los patrones de migración antiguos y contemporáneos dificultan la identificación de unidades poblacionales representativas de acuerdo a la distribución geográfica de ciertas entidades étnicas precolombinas. Además, el conocido fenómeno de cambio de lengua adoptado por muchas sociedades prehispánicas (Adelaar 2004), es sin duda un factor que entorpece la asignación de individuos a unidades poblacionales específicas. Por estas razones, obtuvimos una muestra amplia del área Chachapoya con la finalidad de capturar gran parte del componente ancestral Chachapoya. El 
principal criterio de inclusión de individuos en este grupo fue tener como lugar de origen alguna localidad dentro del área Chachapoya hasta la generación de los abuelos y únicamente aquellos que posean apellidos locales, ya sean de origen nativo (v.g. Zuta, Catpo) o español (v.g., Trauco, Torrejón).

Jívaro. Este grupo está compuesto por pobladores de ascendencia Wampís o Awajún. Ambos grupos amazónicos pertenecen a la familia etnolingüística Jívaro. Durante el Horizonte Tardío (14701532 d.C.), los inkas intentaron conquistarlos; sin embargo, estas poblaciones lograron mantener su independencia (Ungurahui-IWGIA 2010). Como consecuencia de la llegada de europeos a la región, muchos nativos Jívaro se replegaron hacia el norte (Uriarte y Surrallés 2007). Actualmente los Awajún están distribuidos en más de 300 comunidades entre el norte del Perú y el sureste ecuatoriano. Las comunidades Wampís se localizan hacia el lado este de la Cordillera del Cóndor, generalmente en el extremo norte de la provincia de Condorcanqui (Amazonas) y a lo largo del río Morona, así como en la provincia del Datém del Marañón en Loreto. Los criterios de inclusión en este grupo fueron la autoidentificación étnica (Awajún o Wampís), la lengua materna y el lugar de nacimiento hasta la generación de los abuelos.

Huancas. Este grupo representa a los habitantes del pueblo de Huancas muy próximo a la ciudad de Chachapoyas. Ellos son referidos como los descendientes de individuos que migraron desde el valle del Mantaro en los Andes Centrales a esta región alrededor de 1475 d.C. (Schjellerup 2005), quienes se especializaron en la manufactura de cerámica. Para ser incluidos en este grupo se requirió que los padres y abuelos hayan nacido en el pueblo de Huancas.

Cajamarca. En este estudio el término Cajamarca ha sido usado para describir al conjunto de migrantes cuyo lugar de origen de padres y abuelos ha sido alguna de las provincias de la vecina región de Cajamarca. Se ha observado un flujo constante de cajamarquinos hacia la región Amazonas que se ha intensificado en las últimas décadas, como resultado de presiones económicas. Sin embargo, es interesante anotar que elementos culturales Cajamarca han estado presentes en territorio Chachapoya desde antes del Intermedio Tardío.

\subsection{Marcadores genéticos uniparentales y haplogrupos}

Los marcadores uniparentales de $\mathrm{ADN}$ son sexo-específicos, aquellos de la parte no recombinante del cromosoma Y (NRY-DNA), transferidos a través de la línea paterna y marcadores de ADN mitocondrial (mtDNA) transferidos a través de la línea materna (Kayser 2007). Ambas partes del genoma son heredadas en ausencia de recombinación homóloga y por lo tanto permanecen sin modificaciones de una generación, paterna (NRY-DNA) o materna (mtDNA), a otra.

El hombre moderno, gracias a su movilidad, ha sido capaz de colonizar varios espacios geográficos a través del tiempo, desde su salida del continente africano. En este recorrido, el genoma humano ha ido acumulando mutaciones que son de extrema utilidad en estudios de dinámica poblacional ya que ciertas mutaciones están restringidas a regiones geográficas específicas. De esta manera, las mutaciones distintivas que podamos observar para ambos marcadores (NRY-DNA y mtDNA) en poblaciones nativas americanas serán diferentes de aquellas que caracterizan a las poblaciones europeas o africanas. La clasificación de haplogrupos a nivel mundial utiliza estas mutaciones (o marcadores genéticos) para poder asignar una nomenclatura específica. Sin bien actualmente es posible obtener un nivel de resolución detallado que permite caracterizar las ramas terminales de la filogenia materna y paterna, nuestra investigación se concentra únicamente en el nivel de haplogrupo.

Las poblaciones nativas de América están caracterizadas por cuatro haplogrupos mitocondriales etiquetados como A, B, C y D (Horai provincia de. 1993; Torroni et al. 1993). La determinación directa de haplogrupos se efectúa a través de polimorfismos en la región codificante mitocondrial; sin embargo, también se puede emplear polimorfismos en la región no codificante ( $v . g$, 
regiones hipervariables HVR1 y HVR2) para la determinación de haplogrupos. Por ejemplo, en la Región Hipervariable 1 (HVR1), el haplogrupo A se caracteriza por contar con los polimorfismos 16111T-16223T-16290T-16319A, el haplogrupo B tiene mutaciones en las posiciones nucleotídicas 16189C-16217C, el haplogrupo $\mathrm{C}$ tiene tres polimorfismos $16223 \mathrm{~T}-16325 \mathrm{C}-16327 \mathrm{~T}$, y finalmente el haplogrupo D cuenta con los polimorfismos 16223T -16325C -16362C (Forster et al. 1996). Adicionalmente, en la parte noreste de Norteamérica, se ha reportado el haplogrupo X, el que no se ha encontrado en Sudamérica hasta la fecha (Brown et al. 1998; Reidla et al. 2003; Dornelles et al. 2005).

En la línea paterna, existen dos haplogrupos nativos, denominados $\mathrm{C}$ y $\mathrm{Q}$ de acuerdo a la nomenclatura de YCC 2002 (Y cromosome consortium). Específicamente el haplogrupo Q1a3a* (Q-M3) es el más frecuente en poblaciones nativas sudamericanas mientras que las poblaciones norteamericanas muestran elevadas frecuencias de haplogrupo P-M45 (Bortolini et al. 2003). El sublinaje C3b o C-P39 está restringido a una pocas poblaciones nativas americanas (Zegura et al. 2004). Más recientemente, se ha reportado un sub-linaje denominado $\mathrm{C} 3^{*}(\mathrm{C}-\mathrm{M} 217)$, restringido a dos poblaciones del área ecuatoriana (Roewer et al. 2013), siendo el único linaje que no pertenecería al haplogrupo Q.

\subsection{Tipo de muestra}

Se colectó muestras de saliva de pobladores locales considerados como descendientes de los antiguos Chachapoyas $(N=276)$, del grupo amazónico Jívaro $(N=47)$, del pueblo de Huancas $(N=$ $21)$, y de migrantes cajamarquinos en la parte sur de la región Amazonas $(N=34)$. Se informó de los objetivos del estudio a las autoridades regionales y locales, a los representantes comunales, así como a cada participante. Se registró información demográfica hasta la generación de los abuelos y cada muestra fue codificada y mantenida anónima para su procesamiento posteriormente.

Las muestras de saliva fueron recolectadas en tubos Eppendorf conteniendo $1 \mathrm{ml}$ de buffer (0.05M TRIS, 0.05M EDTA pH 8.0, 0.05M sucrosa, 0.1M NaCl, y 1\% SDS 50ml/L), y se usó un protocolo modificado de extracción de ADN basado en alta salinización (Quinque et al. 2006) para recuperar el ADN.

\subsection{Genotipificación y análisis de datos}

En el caso de cromosoma Y, efectuamos la genotipificación de 23 marcadores o STR (short-tamdem repeat, unidades de repetición de una a seis bases), mediante el uso del kit comercial PowerPlex Y23. Los haplotipos han sido depositados en la base de datos mundial de haplotypos de cromosoma Y, YHRD (Y-chromosome STR Haplotype Reference Databasel https://yhrd.org). Los haplogrupos fueron proyectados en base a los haplotipos usando el predictor de haplogrupos Whit Athey's (http://www.hprg.com/hapest5).

En el ADN mitocondrial, se secuenciaron dos regiones hipervariables del segmento no recombinante del ADN mitocondrial, HVR1 (pares de bases: 16,024-16,385) y HVR2 (pares de bases: 72-340). Todas las secuencias han sido depositadas en la base de datos nucelotídica GenBank (http:// www.ncbi.nlm.nih.gov/genbank). Los haplogrupos mitocondriales fueron estimados mediante el uso del predictor Haplogrep Build 16 (http://haplogrep.uibk.ac.at) con información de Phylotree Build 16 (Kloss-Brandstaetter et al. 2010 ; van Oven y Kayser 2009).

Se calcularon índices de diversidad básicos, diversidad haplotípica $(H)$, diversidad nucleotídica/locus (mtDNA: $\pi$, Y-STR: hd) y MNPD (mean number of pairwise differences) para todas las poblaciones estudiadas usando el software Arlequin ver. 3.5.1.2 (Excoffier et al. 2005). Distancias genéticas $\left(\Phi_{S T}\right)$, distribuciones de histogramas denominadas mismatch distributions, al igual que los tests de neutralidad Tajima's $D$ (Tajima 1989) y Fu's $F_{s}$ (Fu 1997) fueron también obtenidos en Arlequin. Las distancias genéticas fueron simplificadas mediante arboles filogenéticos Neighbor Joining (NJ), usando el software MEGA 5 (Tamura et al. 2007). Las diferencias observadas en las frecuencias de haplogrupos fueron resumidas con un análisis de componente principal (principal 
component análisis, PCA) usando XLSTAT (Addinsoft Corp. 17.12. 2015). Con la finalidad de explorar la estructura genética dentro del bosque nuboso, dividimos nuestra muestra Chachapoya en ocho sub-unidades que representan aproximadamente la distribución geográfica de "grupos étnicos Chachapoya», denominados Corobamba, Pomacochas, Chillao, Chachapoya, La Jalca, Leymebamba, Chilchos, y Rodríguez de Mendoza, parcialmente de acuerdo a descripciones etnohistóricas (Espinoza Soriano 1967; Schjellerup 2008). Debemos especificar que en el caso de Corobamba, Pomacochas, Chillao, Chachapoya, y Chilchos, estas etiquetas representan áreas muestrales (compuestas por el agrupamiento de individuos de acuerdo al lugar de nacimiento), que se superponen de alguna manera a los territorios de los grupos étnicos reportados en las fuentes históricas. Por ejemplo, Chillaos representa a las localidades de Luya, Lamud y Olto, entre otros (Tabla S1). Esta forma de agrupar las subpoblaciones responde al criterio geográfico usado por nosotros y es considerada como una de las posibilidades en las que se puede dividir la muestra total Chachapoya. El objetivo de esta división fue explorar de forma preliminar si existen diferencias significativas o no entre estas subunidades.

Adicionalmente a estas cuatro poblaciones estudiadas, se reunió data de referencia de HVR1 (mtDNA) de 76 poblaciones y Y-STR haplotipos de seis a diecisiete loci de 51 poblaciones de nativos americanos de fuentes publicadas (Tabla S2).

\section{Resultados}

\subsection{ADN mitocondrial}

Haplogrupos. En la población Chachapoya los haplogrupos de nativos americanos A, B, C y D (Torroni et al. 1992, 1993, 1994; Horai et al. 1993) constituyen el 89\%. Entre las poblaciones de nuestra área de estudio, la Chachapoya mostró la mayor proporción de haplogrupos no nativos con $11.2 \%$, los que estuvieron ausentes en Huancas y en reducida frecuencia en Jívaro (2\%). Los haplogrupos más frecuentes en todas las poblaciones a excepción de Huancas fueron $\mathrm{B}$ y C. El haplogrupo A fue el más frecuente en Huancas (42.9\%) y el haplogrupo B en la población Jívaro (59.6\%). Es interesante observar que el haplogrupo D está ausente en la población Jívaro (Tabla 1). En la muestra Cajamarca la proporción de haplogrupos B y C es la misma (32.4\%). Debido a que nuestro interés es discutir procesos de dinámica poblacional previos a la conquista europea, excluimos aquellas secuencias que no contenían HVR1 y HVR2, mutaciones características de nativos americanos en los análisis subsecuentes.

Diversidad haplotípica nativo-americana. La diversidad haplotípica en una determinada población es representada por el índice $H$, considerando la más alta diversidad cuando se alcanza el $100 \%$ o $H=1$. Incluyendo ambas regiones hipervariables (HVR1 y HVR2), todas las poblaciones estudiadas tienen altos niveles de diversidad haplotípica. La población Chachapoya muestra uno de los índices más altos $(H=0.9671 \pm 0.0051)$. Los grupos Jívaro $(H=0.9343 \pm 0.0178)$ y Huancas $(H=0.9286 \pm 0.0325)$ exhiben niveles intermedios y el grupo Cajamarca $(H=0.9715 \pm 0.0137)$ posee el más alto índice (Tabla 2 ).

Se observaron también altos niveles de diversidad cuando se usó solamente secuencias de HVR1 (Región Hipervariable 1). Después de emplear métodos de rarefacción, asumiendo $N=20$, en un rango de $h r=0.91$ a $h r=17.10$, las poblaciones Chachapoya ( $h r=12.51)$, Jívaro $(h r=12.13)$, y Cajamarca ( $h r=12.461)$ aún mantienen niveles relativamente altos de diversidad.

En cuanto a los otros índices, la diversidad nucleotídica se encuentra en un rango de $\pi=0.0128 \pm 0067$ en Jívaro a $\pi=0.0160 \pm 0.0081$ en Huancas. Las cuatro poblaciones estudiadas tienen niveles intermedios de diversidad genética cuando son comparadas en el contexto de poblaciones nativas americanas, donde se observa niveles muy altos, v.g. Cheyenne $(\pi=0.0256 \pm 0.0135)$, o muy bajos, como en la población amazónica Aché $(\pi=0.0037 \pm 0.0026)$. De forma similar, los índices MNPD son además altos en nuestras cuatro poblaciones de interés (Tabla S3). 


\begin{tabular}{lcccccc}
\hline Población / Haplogrupo & N & A & B & C & D & Otros \\
\hline Corobamba & 27 & $14.9 \%(4)$ & $40.7 \%(11)$ & $22.2 \%(6)$ & $18.5 \%(5)$ & $3.7 \%(1)$ \\
Pomacochas & 49 & $10.2 \%(5)$ & $53.1 \%(26)$ & $16.3 \%(8)$ & $10.2 \%(5)$ & $10.2 \%(5)$ \\
& 28 & $0 \%$ & $35.7 \%(10)$ & $21.4 \%(6)$ & $25 \%(7)$ & $17.9 \%(5)$ \\
Rodriguez de Mendoza & & & & & \\
Chillao & 40 & $22.5 \%(9)$ & $17.5 \%(7)$ & $25 \%(10)$ & $20 \%(8)$ & $15 \%(6)$ \\
Chachapoyas & 50 & $18 \%(9)$ & $32 \%(16)$ & $16 \%(8)$ & $24 \%(12)$ & $10 \%(5)$ \\
La Jalca & 33 & $18.2 \%(6)$ & $48.5 \%(16)$ & $18.2 \%(6)$ & $3 \%(1)$ & $12.1 \%(4)$ \\
Leymebamba & 38 & $13.1 \%(5)$ & $21.1 \%(8)$ & $31.6 \%(12)$ & $21.1 \%(8)$ & $13.1 \%(5)$ \\
Chilchos & 12 & $0 \%$ & $33.3 \%(4)$ & $41.7 \%(5)$ & $25 \%(3)$ & $0 \%$ \\
\hline Chachapoya (combinado) & 277 & $13.7 \%(38)$ & $35.4 \%(98)$ & $22 \%(61)$ & $17.7 \%(49)$ & $11.2 \%(31)$ \\
\hline Jívaro & 47 & $12.8 \%(6)$ & $59.6 \%(28)$ & $25.5 \%(12)$ & $0 \%$ & $2.1 \%(1)$ \\
Huancas & 21 & $42.9 \%(9)$ & $42.9 \%(9)$ & $4.7 \%(1)$ & $9.5 \%(2)$ & $0 \%$ \\
Cajamarca & 37 & $10.8 \%(4)$ & $32.4 \%(12)$ & $32.4 \%(12)$ & $16.3 \%(6)$ & $8.1 \%(3)$ \\
\hline Total & 382 & $15.9 \%(66)$ & $38.2 \%(158)$ & $23.2 \%(96)$ & $14.2 \%(59)$ & $8.5 \%(35)$ \\
\hline
\end{tabular}

${ }^{1}$ Subunidades Chachapoya en cursiva

${ }^{2}$ Tamaño de población en paréntesis

Tabla 1. Haplogrupos y tamaño de población (ADN mitocondrial)

\begin{tabular}{lcccccccc}
\hline Población & $\mathrm{N}$ & $\boldsymbol{A}$ & $\boldsymbol{b}$ & $S D h$ & $\pi$ & $S D \pi$ & MNPD & SDMNPD \\
\hline Chachapoya & 245 & 99 & 0.9671 & 0.0051 & 0.0157 & 0.0079 & 9.8241 & 4.5125 \\
Jívaro & 46 & 19 & 0.9343 & 0.0178 & 0.0128 & 0.0067 & 8.0141 & 3.7916 \\
Huancas & 21 & 12 & 0.9286 & 0.0325 & 0.0164 & 0.0087 & 10.2445 & 4.8721 \\
Cajamarca & 34 & 22 & 0.9715 & 0.0137 & 0.0141 & 0.0074 & 8.8323 & 4.1756 \\
\hline
\end{tabular}

Tabla 2. Indices de diversidad con ambas regiones hipervariables (HVR1 y HVR2).

Diferenciación entre poblaciones. En genética de poblaciones se emplea un parámetro denominado $\Phi_{S T}$, que nos da información sobre cuán diferentes son dos poblaciones comparadas entre sí. Cuando los valores obtenidos son mayores de 0.05 se puede interpretar que las poblaciones comparadas son diferentes. En el contexto local, la población Chachapoya mostró diferenciación significativa con las muestras Jívaro $\left(\Phi_{S T}=0.059, p<0.01\right)$ y Huancas $(0.057, p<0.01)$ pero no diferenciación significativa con Cajamarca $\left(\Phi_{S T}=0.002, p=0.303\right)$. En el contexto andino, el grupo Chachapoya tiene distancias cortas pero significativas $\left(0.02 \leq \Phi_{S T} \leq 0.05, p \leq 0.05\right)$ con las poblaciones extintas de Chiribaya y con series modernas de Arequipa y Yungay, además de una muestra combinada Quechua - Uros. De otro lado, las comparaciones con Ancash, Tayacaja, y San Martín no mostraron diferenciación significativa $(p \geq 0.05)$. A nivel subcontinental (Sudamérica), la población Chachapoya tiene distancias genéticas cortas pero estadísticamente significativas con poblaciones extintas y modernas de Chile (Norte de Chile antiguo: $\Phi_{S T}=0.0418, p=0.012$, Mapuche y Pehuenche: $\left.\Phi_{S T}=0.0255, p=0.007\right)$, con una población Coya de Argentina $\left(\Phi_{S T}\right.$ $=0.0190, p=0.016)$, con Kalina de la Guyana Francesa $\left(\Phi_{S T}=0.0258, p=0.045\right)$, con Wayuu 
de Colombia $\left(\Phi_{S T}=0.0267, p=0.038\right)$, con Embera $\left(\Phi_{S T}=0.0196, p=0.032\right)$ y Wounan $\left(\Phi_{S T}\right.$ $=0.0527, p=0.003)$ de Panamá, y con un set combinado de las poblaciones norteamericanas hablantes de lenguas Yuman y Pima $\left(\Phi_{S T}=0.0431, p=0.020\right)$. Para simplificar los valores $\Phi_{S T}$ en las comparaciones pareadas, se emplea un método estadístico denominado Neighbor-Joining (NJ) que permite construir arboles filogenéticos; en donde poblaciones con cortas distancias genéticas se agruparan generalmente en el mismo cluster o grupo. En arboles $N J$ es interesante observar al grupo Chachapoya en una posición basal entre la mayoría de las poblaciones Sudamericanas de referencia incluidas en este estudio (Fig. 2). Este patrón es reforzado en un gráfico de análisis de componente principal (PCA) construido en base a las frecuencias de haplogrupos donde la unidad muestral Chachapoya se posiciona muy cerca del centroide. El primer componente principal (PC1) es responsable del $41.76 \%$ de la variación total y correlaciona la frecuencia del haplogrupo $\mathrm{B}$ versus la suma de frecuencias de los demás haplogrupos (A, C, y D). El segundo componente principal (PC 2) representa el 31.33\% de la variación y correlaciona la frecuencia del haplogrupo C versus la suma de los haplogrupos A, B, y D (Fig. 3). En el gráfico se puede identificar un grupo compuesto principalmente por poblaciones andinas del centro y del sur; sin embargo, también se observan poblaciones amazónicas como Xavante, Aché, Matsiguenga, y San Martín. Las cuatro poblaciones estudiadas están distribuidas en el mismo grupo, lo cual refleja la elevada frecuencia del haplogrupo B en su composición (Jívaro fue dividido en Wampís y Awajún únicamente en este análisis).

Historia demográfica. En genética de poblaciones, se usan histogramas denominados distribuciones mismatch (mismatch distributions) para poder observar las distancias moleculares entre pares de haplotipos en una población determinada. Los histogramas representan, para un número de secuencias o haplotipos, la frecuencia de comparaciones pareadas (eje Y) que tienen $0,1,2 \ldots \mathrm{n}$ máximo de diferencias (eje X) (Pereira et al. 2002). La forma particular que adquiere un histograma es altamente influenciada por eventos demográficos antiguos o barridos selectivos (Rogers y Harpending 1992; Slatkin y Hudson 1991). Por ejemplo, es posible observar eventos que reflejan una reducción drástica en el tamaño de la población en el pasado. El patrón de alta diversidad genética en la población Chachapoya observado a través de los índices de diversidad es corroborado por estos histogramas, donde se observan picos a cuatro y seis diferencias. Se registra un evento que denota reducción en la diversidad en el pasado reciente a una diferencia, pero no es drástico (Fig. 4a). Las demás poblaciones de interés tienen patrones similares, sin embargo registran frecuencias menores alrededor de una a cinco diferencias (Fig. 5). A escala continental, la mayoría de las poblaciones incluidas en este estudio exhiben patrones que denotan una reducción drástica en la diversidad, a excepción de algunas series andinas (v.g. Chiribaya, Sicán, Tayacaja, Yungay [información no presentada aquí]).

En estudios de dinámica poblacional también se usan tests de neutralidad que permiten distinguir entre crecimiento poblacional y tamaño de población constante. En este estudio usamos el índice de Tajima llamado "D» y el índice de Fu denominado «Fs». Este último probablemente detecta con mayor sensibilidad expansiones poblacionales de gran magnitud, las cuales son manifestadas a través de valores negativos grandes. Valores positivos, por el contrario, pueden indicar que una determinada población ha experimentado deriva genética (Excoffier et al. 2005; Fu 1997; Tajima 1989). La muestra Chachapoya exhibe valores negativos significativos para ambos índices $(F s=-23.98616, p=0.0018$ y $D=-1.51132, p=0.0309)$, lo cual es consistente con los hallazgos de alta diversidad. En el contexto local, nuestra muestra Cajamarca también ha producido valores estadísticamente significativos en el caso de uno de los índices $\left(F_{s}=-6.35202, p=0.0268\right)$. A nivel continental, pocas poblaciones mostraron valores significativos para ambos índices (v.g., El Salvador, Áncash, Tayacaja, Coya).

Grupos étnicos Chachapoya. Considerar que La Jalca, Leymebamba y Rodríguez de Mendoza aluden al pueblo y caseríos vecinos de donde se obtuvo la muestra (sobre las subunidades ver 2.4. Materiales y Métodos). Cuando la muestra Chachapoya es dividida geográficamente en función a la distribución étnica aproximada de grupos Chachapoya (Tabla S1), se observa variabilidad en las 


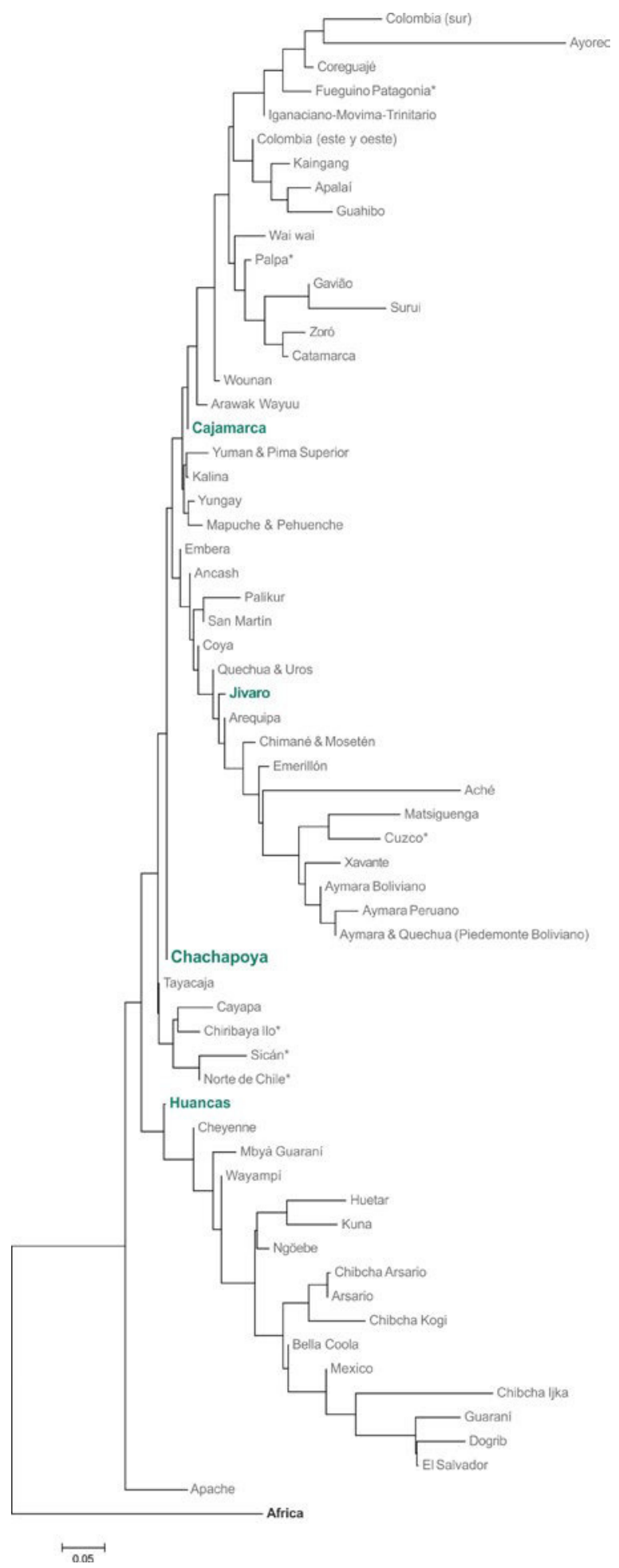

Figura 2. Árbol filogenético (Neighbor-Joining) construido en base a valores $\Phi_{S T}$ para ADN mitocondrial. * Colecciones antiguas 


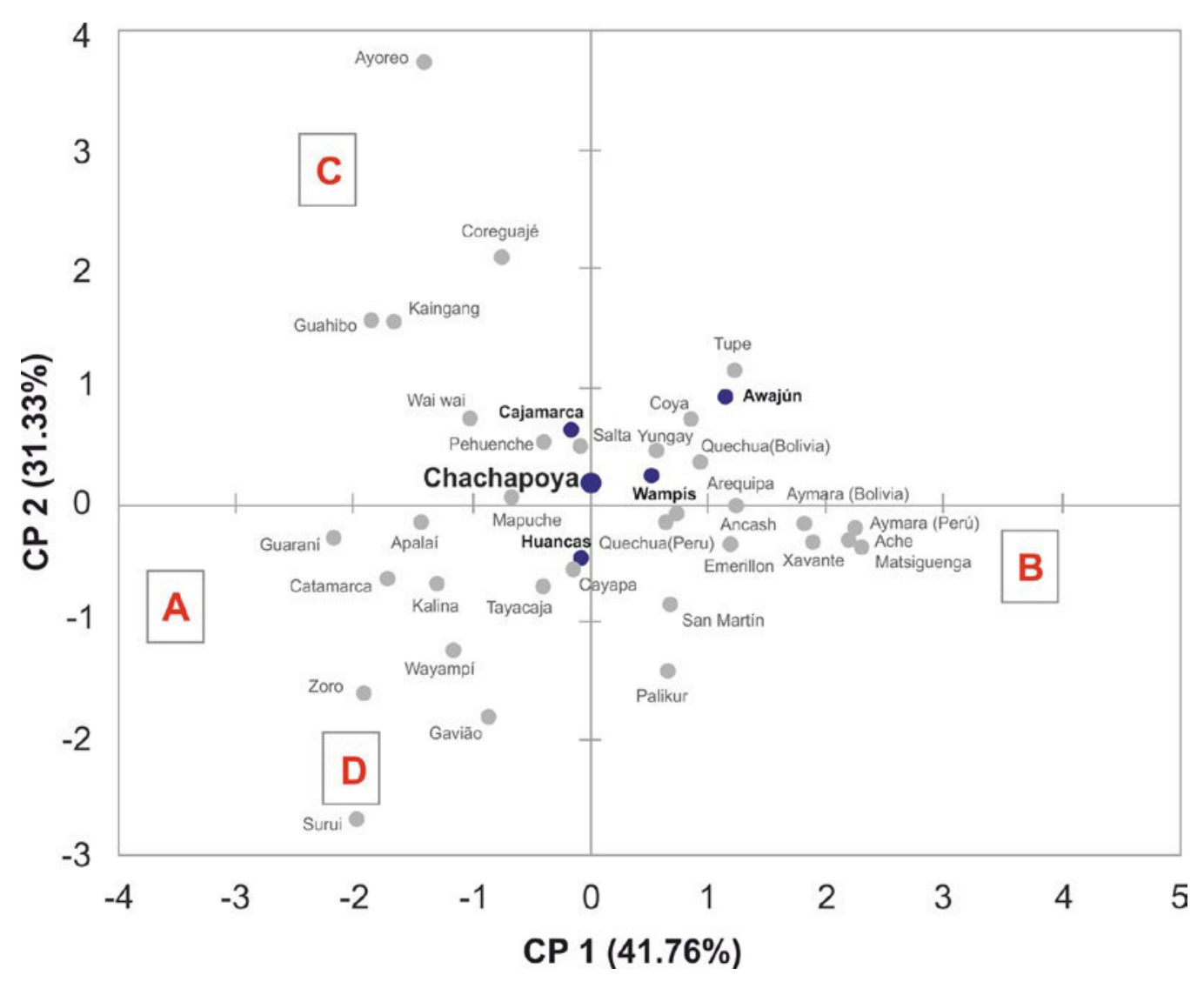

Figura 3. Gráfico de Análisis de Componente Principal (PCA). Nombres de haplogrupos relativo al eje en rojo.

frecuencias de haplogrupos A, B, C y D (Fig. 6). Localmente se calcularon distancias genéticas entre las subunidades, lo cual reveló distancias genéticas significativas entre Pomacochas y Chillao $\left(\Phi_{S T}=\right.$ $0.0745, p=0.0005)$, e igualmente entre Pomacochas y Leymebamba $\left(\Phi_{S T}=0.0549, p=0.0040\right)$. También se observaron grandes distancias genéticas entre Chillao y Rodríguez de Mendoza $\left(\Phi_{S T}\right.$ $=0.0703, p=0.0009)$. Las demás comparaciones produjeron valores no significativos, indicando estrecha afinidad genética entre las subunidades. Adicionalmente, se utilizó AMOVA para identificar estructura poblacional entre las subunidades Chachapoya con la muestra Jívaro. Se obtuvo una ligera reducción de índices $F_{S C}$, de 3.20 a 2.56 ( $\left.p<0.0001\right)$, únicamente cuando Pomacochas es agrupada con Jívaro. A nivel continental, las afinidades genéticas con poblaciones de las Américas tienden a ser muy similares entre las subunidades e igualmente el patrón se asemeja mucho al obtenido cuando dichas subunidades formaban un único grupo. De la misma manera, en árboles filogenéticos todas las unidades Chachapoya tienden a asumir posiciones basales en diferentes clusters (Fig. 7).

\subsection{Cromosoma Y}

Haplogrupos. A diferencia del marcador femenino, existe una menor proporción de haplotipos nativos americanos de cromosoma $\mathrm{Y}$ en todas las subunidades Chachapoya (Fig. 8). El haplogrupo predominante nativo-americano es Q, el cual alcanza un 60\% en la población Chachapoya en su conjunto. Es interesante observar una casi ausencia de linajes foráneos (no Q) en las poblaciones Jívaro (4\%) y Huanca (8\%). La población Cajamarca, por el contrario, posee una gran cantidad de linajes foráneos (52\%) (Tabla 3). 


\begin{tabular}{lccc}
\hline Población/Haplogrupo & $\mathrm{N}$ & $\mathrm{Q}$ & Otros \\
\hline Corobamba & 7 & $85.7 \%(6)$ & $14.3 \%(1)$ \\
Pomacochas & 21 & $71.4 \%(15)$ & $28.6 \%(6)$ \\
Rodríguez de Mendoza & 13 & $23.1 \%(3)$ & $76.9 \%(10)$ \\
Chillao & 14 & $85.7 \%(12)$ & $14.3 \%(2)$ \\
Chachapoyas & 24 & $50 \%(12)$ & $50 \%(12)$ \\
La Jalca & 15 & $86.7 \%(13)$ & $13.3 \%(2)$ \\
Leymebamba & 19 & $36.8 \%(7)$ & $63.2 \%(12)$ \\
\hline Chachapoya (combinado) & $\mathbf{1 1 3}$ & $\mathbf{6 0 . 2 \% ( 6 8 )}$ & $\mathbf{3 9 . 8 \% ( 4 5 )}$ \\
\hline Jívaro & 24 & $95.8 \%(23)$ & $4.2 \%(1)$ \\
Huancas & 12 & $91.7 \%(11)$ & $8.3 \%(1)$ \\
Cajamarca & 25 & $48 \%(12)$ & $52 \%(13)$ \\
\hline Total & 174 & $65.5 \%(114)$ & $34.5 \%(60)$ \\
\hline${ }^{1}$ Subunidades Chachapoya en cursiva & & & \\
${ }^{2}$ Tamaño de población en paréntesis & & &
\end{tabular}

Tabla 3. Haplogrupos y tamaño de población (cromosoma Y)

\begin{tabular}{lcccccccc}
\hline Población & $\mathbf{N}$ & $\mathbf{A}$ & $\mathbf{h}$ & SDh & Hd loci & SD Hd loci & MNPD & SDMNPD \\
\hline Chachapoya & 68 & 63 & 0.9974 & 0.0032 & 0.5320 & 0.2694 & 12.2366 & 5.5901 \\
Jívaro & 23 & 17 & 0.9170 & 0.0531 & 0.3774 & 0.2009 & 8.6798 & 4.1457 \\
Huancas & 10 & 8 & 0.9333 & 0.0773 & 0.4783 & 0.2664 & 11.0000 & 5.4249 \\
Cajamarca & 11 & 11 & 1.0000 & 0.0388 & 0.5557 & 0.3039 & 12.7818 & 6.2023 \\
\hline
\end{tabular}

Tabla 4. Indices de diversidad con 23 loci (cromosoma Y)

Diversidad haplotípica nativo-americana. En el contexto de las Américas, incluyendo 23-loci, observamos niveles relativamente altos de diversidad haplotípica en todas las poblaciones estudiadas $(H>0.92$, Tabla 4). Las poblaciones Chachapoya y Cajamarca exhiben los valores más altos, con $H=0.9974 \pm 0.0032$ y $H=1 \pm 0.0388$ respectivamente. Nuevamente, excluimos los haplotipos foráneos, ya que el énfasis es en el componente nativo-americano. Igualmente, en comparaciones a nivel continental pero usando un subgrupo de poblaciones peruanas con nueve loci (DYS19-DYS385 I-DYS385 II-DYS389 I-DYS389 II-DYS390-DYS391-DYS392-DYS393), Chachapoya $(H=0.9833 \pm 0.0066)$ y Cajamarca $(H=1 \pm 0.0388)$ muestran elevada diversidad haplotípica, similar a la población de Junín $(H=1 \pm 0.0302)$ o a la población Quechua-hablante del Cusco $(H=0.9613 \pm 0.0194)$. Las otras dos poblaciones estudiadas, Jívaro $(H=0.8972 \pm 0.0503)$ y Huanca $(H=0.9111 \pm 0.0773)$, tienen niveles relativamente menores de diversidad, pero aún más altos que muchas poblaciones amazónicas de Sudamérica, las que generalmente tienen $H \leq 0.85$. La diversidad haplotípica por loci (haplotype diversity over loci, $h d$ ) en el contexto americano muestra niveles moderados en las poblaciones Chachapoya $(h d=0.5309 \pm 0.2909)$ y Cajamarca $(h d=$ $0.5616 \pm 0.3308)$. Índices mucho menores son observados en los casos Jívaro ( $h d=0.4515 \pm 0.2598)$ y Huancas $(h d=0.4494 \pm 0.2748)$. Patrones similares son observados con el índice MNPD. La diversidad haplotípica después de rarefacción $(h r)$ a $N=10$, incluyendo poblaciones peruanas de 


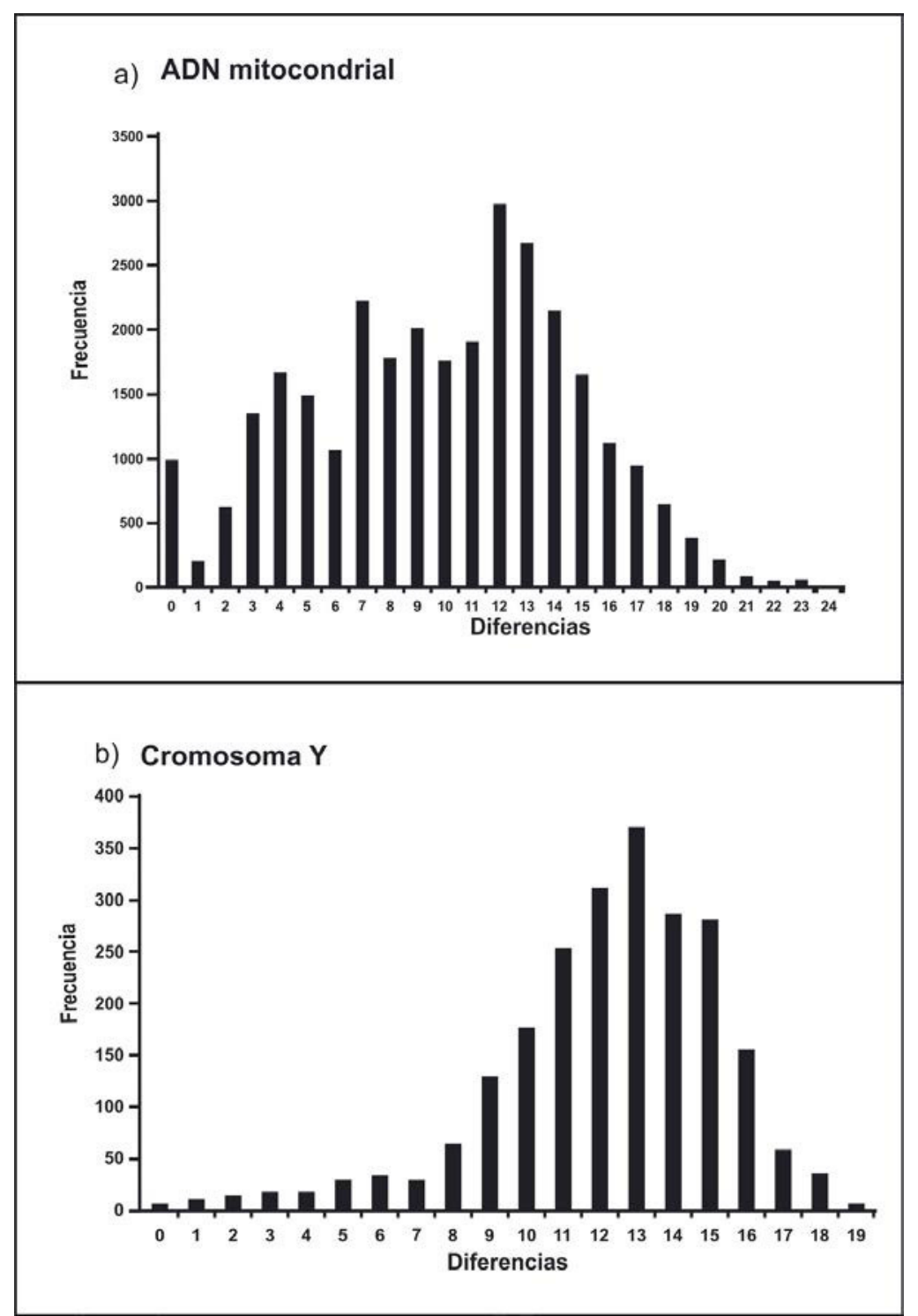

Figura 4. Distribuciones mismatch para: a) ADN mitocondrial, b) Cromosoma $Y$.

relevancia, también muestran a Chachapoya y Jívaro entre los grupos más diversos, con $h r=17.554$ and $h r=13.156$, respectivamente (Tabla S4). Rarefacción es un método usado para comparar diversidad genética en varias poblaciones con diferentes tamańos de muestra ( $v . g$. dos poblaciones, una con $N=10$ and otra con $N=70)$.

Diferenciación genética. Incluyendo 23-loci, la población Chachapoya tiene distancias genéticas cortas pero significativas con Huancas $\left(\Phi_{S T}=0.0447, p=0.0227\right)$ y Cajamarca $\left(\Phi_{S T}=0.0430, p=\right.$ $0.0117)$. La comparación con Jívaro produjo un valor grande y significativo $\left(\Phi_{S T}=0.1673, p<\right.$ 0.0001). Cuando las comparaciones incluyen nueve loci (DYS19-DYS385 I-DYS385 II-DYS389 I-DYS389 II-DYS390-DYS391-DYS392-DYS393), el grupo Chachapoya muestra distancias genéticas no significativas cuando se compara con Huancas $\left(\Phi_{S T}=0.0181, p=0.1946\right)$. Sin 

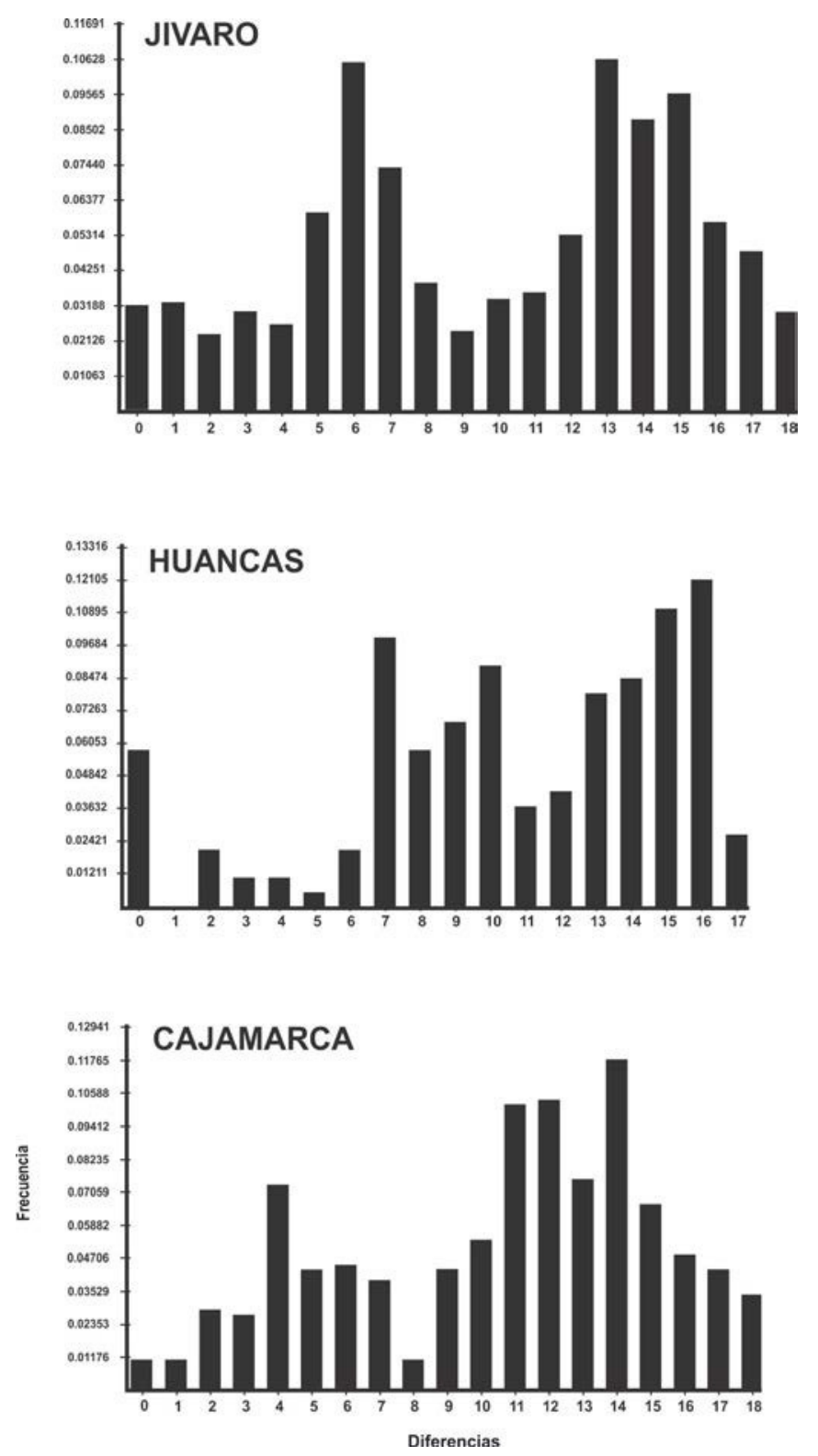

Figura 5. Distribuciones mismatch en Jivaro, Huancas, y Cajamarca (ADN mitocondrial).

embargo, exhibe distancias genéticas grandes pero significativas con Cajamarca $\left(\Phi_{S T}=0.0706\right.$, $p=0.0052)$ y Jívaro $\left(\Phi_{S T}=0.0996, p<0.0001\right)$. En el contexto andino, solo una comparación de una muestra general de Perú (varias regiones) produjo un valor pequeño pero altamente significativo $\left(\Phi_{S T}=0.0522, p<0.0001\right)$. A nivel continental, solamente se observó distancias genéticas cortas pero significativas en la comparación con la población Mapuche $\left(\Phi_{S T}=0.0494, p<0.0001\right) \mathrm{y}$ Tehuelche $\left(\Phi_{S T}=0.0506, p=0.027\right)$ de Chile. Este patrón se mantiene incluso cuando incrementamos el número de marcadores (15-loci o 17-loci, data no presentada aquí). La falta de afinidades de la muestra Chachapoya con otras poblaciones de Sudamérica se ve reflejada en los árboles filogenéticos Neighbor-Joining (NJ), usando loci data donde la población Chachapoya no se encuentra 


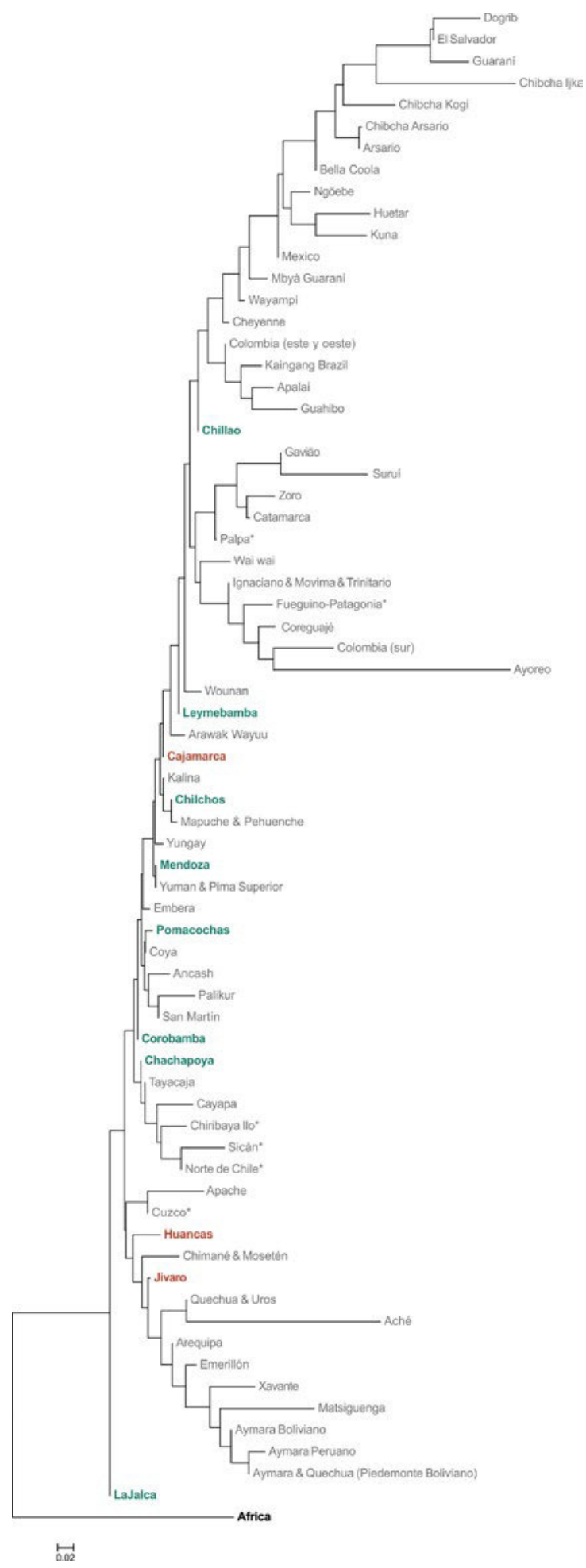

Figura 6. Árbol filogenético (Neighbor-Joining) de subunidades Chachapoya construido en base a valores $\Phi_{S T}$ (ADN mitocondrial). 
en el grupo «andino», sino que se ubica en una rama independiente junto a Huancas y Yanomami, a pesar de ser genéticamente distante con este último (Fig. 7).

Historia demográfica. El histograma (mismatch distribution) en Chachapoya muestra un consistente incremento en las frecuencias desde cero a seis diferencias, lo que no implica una reducción drástica de la diversidad genética (Fig. 4b).

Grupos étnicos Chachapoya. Para observar si existe diferenciación entre los grupos étnicos Chachapoya, en el caso de cromosoma Y, también calculamos distancias genéticas $\left(\Phi_{S T}\right)$ y efectuamos tests AMOVA (Analysis of Molecular Variance). El grupo de La Jalca fue el único que mostró consistentemente distancias genéticas grandes con Pomacochas $\left(\Phi_{S T}=0.1335, p<\right.$ $0.0001)$, Chilchos, Leymebamba $\left(\Phi_{S T}=0.1255, p<0.0001\right)$, Chillao $\left(\Phi_{S T}=0.1309, p<0.0001\right)$, y Chachapoya $\left(\Phi_{S T}=0.0899, p=0.0180\right)$. La comparación entre Chillao y Pomacochas también produjo distancias relativamente grandes $\left(\Phi_{S T}=0.0815, p<0.0001\right)$. Las demás comparaciones produjeron valores $\Phi_{S T}$ no significativos o distancias genéticas cortas. A diferencia de la evidencia mitocondrial, los análisis jerárquicos AMOVA a este nivel no mostraron valores $F_{S C}$ significativos cuando las subunidades norteñas (Pomacochas, Corobamba, y Chillao) fueron agrupadas con Jívaro. A nivel continental todas las subunidades tienen distancias genéticas largas con otras poblaciones de las Américas. En árboles filogenéticos, las subunidades Chachapoya tienden a agruparse en un único cluster cerca a la raíz, con ninguna asociación a otra población ya sea de origen andino o amazónico (Fig. 8).

\section{Discusión}

\subsection{Los Chachapoyas en el contexto local y regional}

Uno de nuestros objetivos fue entender a la población Chachapoya moderna en el contexto de otros grupos del noreste andino. Incluimos entonces a la población amazónica Jívaro, al enclave Huanca y a la población Cajamarca de la región vecina del mismo nombre.

Anteriormente pusimos en evidencia la influencia de elementos amazónicos en la iconografía Chachapoya, un fenómeno además recurrente en los Andes desde períodos muy tempranos. Sabemos que existen innumerables grupos étnicos de origen amazónico que ocupan territorios adyacentes a los dominios de los Chachapoyas. En ese sentido, buscamos evaluar la posibilidad de flujo genético entre la población Chachapoya y el grupo amazónico Jívaro moderno. A pesar de que la lengua usada por los Chachapoyas no sobrevivió a las dramáticas transformaciones sociales y culturales de la segunda mitad del siglo XVI, lingüistas y arqueólogos han sugerido que los Jívaros históricos compartían algunos topónimos al igual que otras características culturales con los Chachapoyas (Taylor 1996, 2000; Guffroy 2006; Koschmieder 2012). La data genética, en ambos marcadores (ADN mitocondrial y cromosoma $\mathrm{Y}$ ), ha mostrado que los Chachapoyas y los Jívaros se encuentran genéticamente distantes. Debemos considerar aquí que los genes, tanto como los elementos culturales, siguen trayectorias y grados de evolución distintos. Sin duda, incorporar muestras de los Jívaros históricos puede ayudar a refinar estos hallazgos.

La arqueología regional ha mostrado que los Chachapoyas mantuvieron interacciones con sociedades cajamarquinas, incluso antes del Período Intermedio Tardío (1000-1470 d.C.). Existe abundante cerámica de estilo Cajamarca en la mayoría de sitios Chachapoya investigados hasta hoy (Ruiz 1972; Schjellerup 2005; Church y von Hagen 2008), lo cual no sólo apunta a intensos contactos entre estas dos áreas culturales, sino que también podría trascender del plano cultural al biológico. De hecho, durante el tiempo de los inkas, mitmaqkuna Cajamarca fueron relocalizados en territorio Chachapoya (Schjellerup 2005). Los marcadores uniparentales indican estrecha afinidad genética entre la gente Chachapoya y Cajamarca; sin embargo, no sabemos si esto refleja fenómenos antiguos o modernos, pues desde la segunda mitad del siglo pasado hasta ahora, se ha observado una fuerte migración cajamarquina hacia el departamento de Amazonas. 


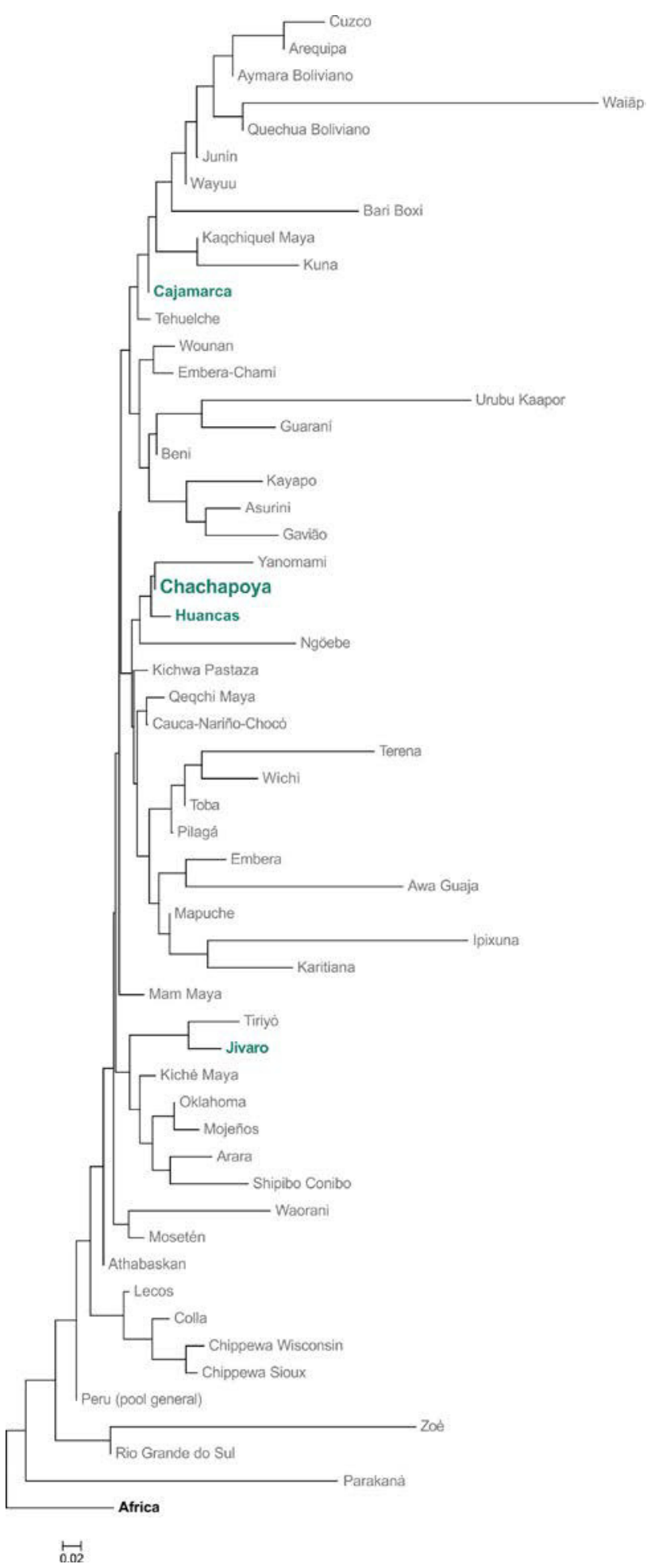

Figura 7. Árbol filogenético (Neighbor-Joining) construido en base a valores $\Phi_{S T}$ para cromosoma $Y$ (9-loci). 


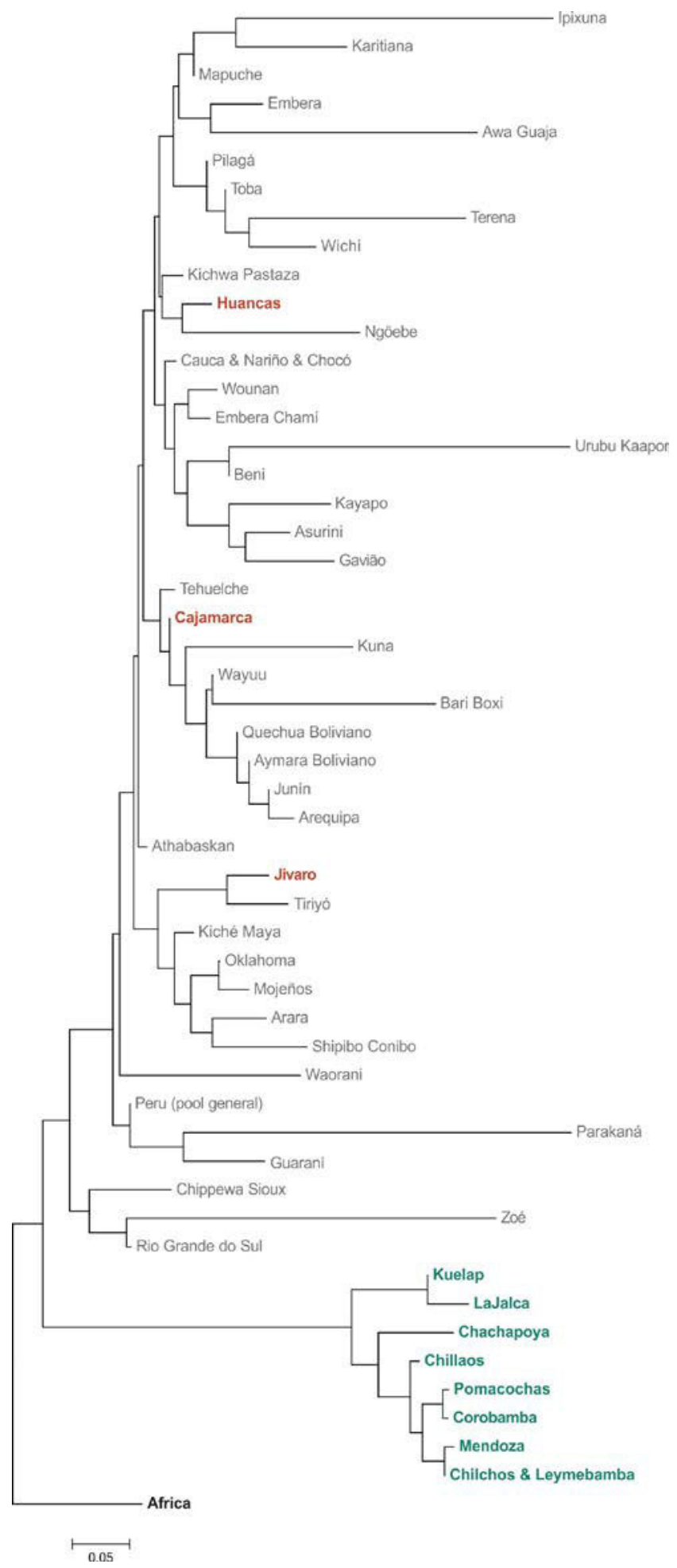

Figura 8. Árbol filogenético (Neighbor-Joining) de subunidades Chachapoya construido en base a valores $\Phi_{S T}$ para Cromosoma Y (9-loci). 
La población del pueblo de Huancas ha sido considerada como un enclave originario del departamento de Junín en el Perú central. Los habitantes de Huancas se especializaron en la manufactura de cerámica desde períodos prehispánicos (Colin 1907) y son muy conocidos por esta actividad incluso hoy en día. Considerando que esta población foránea se estableció en esta región durante el tiempo que los inkas estuvieron expandiéndose en la sierra central del Perú, esperábamos encontrar distancias genéticas cortas entre la población Chachapoya y la muestra de Huancas. El transcurrir de más de 20 generaciones debe haber permitido un intenso mestizaje entre las poblaciones locales y los Huancas implantados en la región. La evidencia genética apoya esta idea en el caso de la línea paterna; sin embargo, el ADN mitocondrial indica que aún existe cierta diferenciación $\left(\Phi_{S T}=\right.$ $0.057, p<0.01)$. Estas trayectorias divergentes por cada marcador están probablemente vinculadas al tipo de alianzas matrimoniales aún vigentes en esta población.

Cuando dividimos la muestra Chachapoya moderna de acuerdo a la distribución aproximada de "grupos étnicos Chachapoya», observamos que algunas sub-unidades tienden a diferenciarse. En el caso del marcador femenino, identificamos ausencia o casi ausencia $(N=1)$ de ciertos haplogrupos en unidades étnicas específicas. En cuanto a distancias genéticas, los subgrupos Pomacochas y Chillao fueron los que más se diferenciaron de las otras subunidades. De otro lado, la data de cromosoma Y mostró que el grupo de La Jalca se diferencia significativamente de las otras subunidades. Estos resultados guardan coherencia con las fuentes etnohistóricas, que describen a los Chachapoyas como un agregado de varios grupos étnicos, y de hecho nueva evidencia arqueológica apunta a diferencias en atributos materiales en este territorio (Koschmieder 2008, 2010). Anteriormente, esta hipótesis en torno a la diversidad al interior de la entidad cultural denominada Chachapoya también había sido evaluada por Nystrom, quien reportó escasas barreras para el flujo génico entre estas subunidades en base a rasgos métricos en el esqueleto (Nystrom 2006). Debemos indicar que si bien los marcadores esqueléticos pueden ser usados para hacer este tipo de inferencias, existen ciertas limitaciones en su uso debido a que el fenotipo es altamente influenciado por factores medioambientales, entre otros. Data concluyente sobre esta heterogeneidad puede únicamente ser obtenida mediante estudios de ADN antiguo sumada a información isotópica y dependerá de la disponibilidad de muestras de colecciones representativas de la región.

\subsection{La población Chachapoya en el contexto sudamericano}

Mediante este estudio hemos podido identificar diversidad genética nativo-americana singular en esta región del bosque nuboso, particularmente en el caso del $\mathrm{ADN}$ mitocondrial. Al igual que en muchas otras poblaciones de la Américas, ha sido posible observar una mayor proporción del componente foráneo (mayormente europeo) en los linajes de cromosoma Y (40\%). Este fenómeno de flujo genético asimétrico, v.g. Chachapoya: mitocondrial=11\%, Y=40\%, es un conocido fenómeno reportado en otras poblaciones nativas americanas, el cual refleja la historia de conquista europea durante la segunda mitad del siglo XVI (Seielstad 2000; Bolnick et al. 2006; Mendizabal et al. 2008;). Estas proporciones tienden a variar dependiendo del grado de mestizaje de las poblaciones estudias. En relación al componente nativo-americano, todas las poblaciones estudiadas muestran variación en las proporciones de haplogrupos (linajes) A, B, C y D. Es importante señalar que entre las poblaciones estudiadas aquí, el haplogrupo B, ampliamente distribuido en los Andes, es el más común. Generalmente las proporciones de haplogrupos (A-D) en cada población en América varía geográficamente (Bisso-Machado et al. 2012). Sabemos, por ejemplo, que poblaciones norteamericanas de América Central y del norte de Sudamérica carecen de haplogrupo D o lo tienen en muy baja proporción (Malhi et al. 2003), lo cual también ocurre en la población Jívaro, donde está ausente.

Como preámbulo a la discusión de los altos niveles de diversidad genética hallados en los Chachapoyas, es importante brindar primero el contexto histórico local. Es ampliamente sabido que los inkas (1470-1532 d.C.) aplicaron la política de mitmaq también en el territorio Chachapoya tanto por cuestiones estratégicas como de control. En las fuentes históricas, se ha 
reportado que mitmaqkuna de origen Chachapoya fueron trasladados hacia al menos dieciocho ubicaciones diferentes y tan lejos como Argentina y Bolivia (Schjellerup 2005; Espinoza Soriano 2006). En general, los estudios etnohistóricos apuntan a una considerable reducción en las poblaciones locales durante aquella época (Cook 2010). Incluso, a pesar de no proporcionar evidencia contundente, algunos investigadores indican que más del $50 \%$ de la población local Chachapoya fue relocalizada (Espinoza Soriano 1988; Lerche 1995). La documentación de la época, sin embargo, no cuenta con detalles como las localidades de origen y la proporción de género en estos segmentos de las poblaciones locales (Schjellerup 2005). De igual manera, sabemos que mitmaqkuna de otras regiones fueron trasladados a diferentes partes del territorio Chachapoya; sin embargo, el número de migrantes en esta región pareciera no haber sido tan significativo (Schjellerup 2005).

Con la llegada de los españoles, la población nativa de América se redujo no únicamente debido a enfrentamientos bélicos y enfermedades sino, además, debido a sobre explotación de la fuerza de trabajo local. Un estudio etnohistórico ha reportado que entre los años 1570 y 1600, los Andes nororientales sufrieron un colapso demográfico más severo que otras regiones de los Andes (Cook 2010). Aparentemente, el segmento masculino de la población fue afectado más dramáticamente, ya que los hombres se reclutaban como fuerza militar. La casi incansable búsqueda del El Dorado por las huestes españolas durante los años inmediatos a la conquista es un claro ejemplo de enlistamiento de hombres en las tropas españolas (Schjellerup 2005). En la parte sur del territorio Chachapoya, se ha sugerido que durante los años de intensa ocupación española en la región, muchos individuos se replegaron hacia las densas forestas tropicales hacia el norte y hacia el este, con la finalidad de evadir el control español (Church 1996; Vázquez de Espinosa 1969 [1620]). Otro ejemplo en el que se ve afectado el segmento masculino de la población de un asentamiento, es el evento acaecido en Kuélap, donde se ha registrado el asesinato masivo de hombres jóvenes y niños (Toyne y Narváez Vargas 2014). Estos acontecimientos, brevemente expuestos aquí, indican una drástica reducción de la población del bosque nuboso (Lerche 1995; Church 1996; Schjellerup 2005; Cook 2010) y sugieren que al examinar las poblaciones modernas de la región deberíamos encontrar una significativa reducción de la diversidad genética en el área.

En el contexto americano, cuando examinamos únicamente el componente nativo-americano, el grupo Chachapoya exhibe alta diversidad haplotípica en ambos sistemas (mitocondrial y cromosoma Y). Esto es apoyado además por los resultados de los tests de neutralidad (v.g. valores negativos grandes de los índices Fu’s Fs y Tajima's $D$ ) e histogramas unimodales. Estos patrones son raramente observados en poblaciones nativas americanas, las cuales generalmente exhiben histogramas que denotan una notable reducción de la diversidad genética. En el caso de ADN mitocondrial, únicamente cuatro poblaciones, de un total de 76 , muestran histogramas similares al grupo Chachapoya (data no mostrada).

Existen algunas explicaciones potenciales al fenómeno de altos niveles de diversidad observados en el nororiente peruano. De haber existido una reducción en el tamaño de poblaciones, que podría ser descrito como drástico en escala humana, este no habría sido lo suficientemente severo para reducir la diversidad genética. Sabemos que los efectos de cuello de botella (bottleneck) son determinados por cierto número de factores y que la diversidad genética puede persistir aún en situaciones que parecieran ser severas (por ejemplo ver (Kekkonen et al. 2012). Debido a que la muestra Chachapoya tiene niveles de diversidad genética inusuales, una característica observada en muy pocas poblaciones sudamericanas, nos obliga a considerar además otros factores más allá de las dinámicas de cuello de botella.

La primera posibilidad sería que el grupo Chachapoya haya albergado elevados niveles de diversidad genética desde antes del Intermedio Tardío. En la literatura arqueológica, se indica que las poblaciones que predatan a los inkas en la región habrían sostenido grandes tamaños poblacionales (Church y von Hagen 2008; Schjellerup 2005); sin embargo, existe escasa información documental, y el tamaño de los asentamientos en sí mismos no puede apoyar esta idea ya que no existe una secuencia cronológica bien definida para toda la región. 
Durante el período colonial temprano, los conquistadores españoles emprendieron decenas de expediciones en búsqueda de El Dorado, usando como puntos de partida en el norte a las ciudades de Quito y Chachapoyas (Saignes 1999). Esto pone en evidencia no solo la importancia de estos asentamientos, sino, además, la presencia de individuos de diverso origen étnico que atravesaron el territorio Chachapoya, muchos de los cuales podrían haber permanecido en la región. En el año 1549, alrededor de 300 individuos tupí («indios Brasiles») llegaron al área de Chachapoyas. Ellos habrían salido del litoral brasileño y después de varios años, usando como vías el río Amazonas y Marañón, arribaron a Santiago de los ocho valles de Moyobamba (Nunes 1992; Saignes 1999). Si bien se hace un recuento de la llegada de un considerable número de población Tupí, no se tiene más información relevante sobre el destino de esta población, como, por ejemplo, si decidieron permanecer en el área como una unidad o si el grupo se dividió y diseminó más allá de los dominios de los Chachapoyas. Estos dos eventos, sucedidos durante los años de fricción entre las poblaciones locales y los españoles, bien podrían haber influido en las dinámicas de flujo genético en la región, incrementando la diversidad en las poblaciones locales.

Otro escenario involucraría a la política de reducciones de indios (Medina 1975) implementada en el Perú colonial y a un probable efecto inesperado, o antes no evaluado, que podría haber incrementado la diversidad genética en áreas como esta. Siguiendo esta idea, cabe señalar que un estudio etnohistórico basado en documentación del siglo XVI y XVII muestra un mapa preliminar en donde más de diez grupos étnicos se encontrarían ocupando un área relativamente pequeña al noreste del territorio Chachapoya (Espinoza S. 1973). Esto, sumado a la existencia de otros grupos v.g. jivito y cholón, distribuidos al este, proporciona evidencia no sólo de la alta diversidad étnica en dichas áreas, sino también documenta el origen de potenciales migrantes hacia el territorio de los chachapoya. En el contexto de las reducciones esto significaría la incorporación de individuos de diversas etnias para formar unidades tributarias más grandes, ya que usualmente se describe a la región como poco atractiva en términos tributarios (Cook 2010). Sobre esto, es necesario contar con documentación histórica más detallada respecto a dichos eventos para poder evaluar esta hipótesis.

La última posibilidad sería que, debido probablemente a las características geográficas y topográficas de este segmento de los Andes, la diversidad de las poblaciones de la región podría haber sido enriquecida continuamente gracias al movimiento de personas a través de la región, durante y después del colapso demográfico reportado para esta área. Para poder determinar qué factores contribuyeron significativamente a potenciar la diversidad genética en los chachapoyas y cuando sucedieron estos eventos, es necesario refinar nuestros hallazgos con marcadores que brinden mayor resolución. Considerando estas limitaciones, el análisis de la diversidad genética moderna ha mostrado, en general, que el tamaño de la población Chachapoya no sufrió deriva genética en el pasado. En este sentido, el grupo Chachapoya se asemeja mucho a otras poblaciones andinas, pero, sin embargo, existen otras características que lo hacen bastante singular, tal como explicamos a continuación.

En un contexto más amplio, comparamos a los chachapoyas con otras poblaciones nativas americanas para poder develar afinidades genéticas que nos ayuden a inferir sus probables orígenes. El marcador femenino (ADN mitocondrial) muestra que los chachapoyas tienen afinidades genéticas con varias poblaciones de diverso origen y amplia distribución geográfica. En Perú tiene afinidades con las poblaciones modernas de Yungay, Áncash, Tayacaja y San Martín. También tienen distancias genéticas reducidas con las poblaciones extintas de Chiribaya, Palpa y Cuzco. En Sudamérica el patrón es similar, donde los Chachapoyas mantienen afinidad genética con poblaciones andinas (v.g. Coya) y también amazónicas (v.g. Embera, Arawak-Wayuu, Kalina), además de otras poblaciones geográficamente más distantes, como los Mapuche en Chile y grupos del Norte de América (hablantes de lenguas Yuman y Upper Piman). En árboles filogenéticos, la población Chachapoya (integrada y en subunidades) tiende a sumir posiciones basales entre gran parte de las poblaciones de referencia incluidas en el estudio. Este patrón es similar al obtenido mediante el gráfico de PCA, extrapolado en base a las frecuencias de haplogrupos, en donde el grupo Chachapoya se ubica muy 
cerca del centroide (intersección de los dos ejes). Las afinidades con un gran número de poblaciones en las Américas, además de su posición basal, pueden indicar que los Chachapoya modernos han retenido diversidad genética mitocondrial común en varias poblaciones provenientes de diferentes regiones. Esto puede implicar persistencia de diversidad de los primeros grupos que colonizaron las Américas, o bien altos niveles de flujo genético en la región desde diferentes flancos, o ambos. No existen reportes o información histórica específica que documente grandes migraciones hacia el territorio de los Chachapoya, con la salvedad de la migración Tupí antes mencionada.

En ese sentido, el hecho de que el grupo Chachapoya tenga afinidades genéticas con poblaciones de diferentes familias lingüísticas (v.g. Tupí, Caribe, Arawak, Chibcha, Quechua) y tan lejos como América del Norte, América Central y el Cono Sur (v.g. Mapuche), puede sugerir que esta diversidad común (linajes) fue retenida en períodos preinka e inka. Es decir que tal vez, algunos linajes muy antiguos hayan sobrevivido en el área. En la literatura sobre la ocupación humana en Sudamérica, existe una hipótesis que propone una ruta de dispersión hacia el sur desde los Andes orientales del norte del Perú y el sur de Ecuador (Sauer 1944; Lothrop 1961; Hester 1966), la cual fue revisada recientemente en función a industrias líticas recuperadas en la región (Church y von Hagen 2008). Esto pone en evidencia la importancia geográfica de este estrecho de los Andes, incluso en períodos muy tempranos, cuando grupos móviles transitaban por esta región. De hecho, varios investigadores consideran el territorio Chachapoya como una intersección importante para el acceso e intercambio de productos provenientes de diferentes lugares, lo cual es más evidente cuando las sociedades sedentarias más complejas se consolidaron en esta área (Church y von Hagen 2008; Schjellerup 2005; Clasby 2014). El hecho de que la altitud de la cordillera en esta región varía rápidamente y se estrecha, formando una serie de corredores y haciendo más fácil el movimiento horizontal ( $v . g$. de la costa a la Amazonía), ciertamente dota de singularidad al este territorio. En ese sentido, el escenario más probable tal vez haya involucrado el constante enriquecimiento del pool genético local a través del tiempo.

Cuando examinamos el componente paterno, el grupo Chachapoya tiene afinidades con un número reducido de poblaciones, con una muestra de Perú que incluye individuos de distintas regiones y con dos poblaciones chilenas. A diferencia del marcador femenino, en árboles filogenéticos, el grupo Chachapoya no se agrupa con poblaciones de origen andino o amazónico, sino que aparece en una rama independiente. Hemos mencionado anteriormente que los eventos de despoblación tuvieron un mayor impacto en el segmento masculino local, lo cual podría haber resultado en afinidades con muy pocas poblaciones sudamericanas.

\section{Conclusiones}

Es posible que en el bosque nuboso, muchos grupos humanos usaran los corredores formados entre el sur de Ecuador y el norte de Perú por milenios. Una vez que los asentamientos sedentarios se formaron en este territorio, sus habitantes habrían estado constantemente en contacto con grupos móviles provenientes de diferentes direcciones. La intensificación de estos contactos a través de los años, durante el florecimiento de sociedades más complejas, habría permitido la formación de redes de intercambio entre las élites, lo cual habría garantizado el movimiento de bienes desde y hacia los asentamientos de la región, tal como ha sido reportado por varios investigadores (Schjellerup 2005; Church y von Hagen 2008; Clasby 2014). En este contexto, los resultados aquí presentados sugieren que las poblaciones sedentarias de esta región (tempranas o tardías), habrían enriquecido con mayor intensidad su pool genético a diferencia de otras poblaciones en ecosistemas puramente «andinos» o «amazónicos». Si bien el tipo de data aún no nos permite inferir qué factores habrían contribuido más significativamente a lograr elevados niveles de diversidad genética observados en las poblaciones locales modernas, y ubicar cronológicamente las transformaciones en el tamaño de las poblaciones locales, este estudio representa un primer paso con miras a develar la intrincada historia poblacional de los chachapoyas y otros grupos del bosque nuboso. 


\section{Agradecimientos}

Nuestro agradecimiento al Gobierno Regional de Amazonas y a la Municipalidad Provincial de Chachapoyas por contribuir financieramente al desarrollo de la etapa de colecta de muestras. El Gobierno Regional de Amazonas brindó además apoyo institucional y logístico en algunas localidades durante el trabajo de campo. A todos los funcionarios y personas naturales en cada provincia que mostraron interés y que proporcionaron su respaldo durante este trabajo. Nuestro más sincero agradecimiento a todos los participantes en el estudio, sin quienes esta investigación no habría sido posible. Finalmente, nuestra gratitud al Centro para la Movilización Internacional (Center for International Mobility, CIMO), que proporcionó una beca a Evelyn Guevara durante la etapa de laboratorio (\# TM-12-8372).

\section{REFERENCIAS}

\section{Adelaar, W.F.H.}

2004 Languages of the Andes. West Nyack, NY, Cambridge University Press.

Batista, O., Kolman, C.J. y Bermingham, E.

1995 Mitochondrial DNA diversity in the Kuna amerinds of Panama. Human Molecular Genetics 4(5), 921929.

Bolnick, D.A., Bolnick, D.I. y Smith, D.G.

2006 Asymmetric Male and Female Genetic Histories among Native Americans from Eastern North America, Molecular Biology and Evolution 23(11), 2161-2174.

Bortolini, M.C., F.M. Salzano, M.G. Thomas, S. Stuart, S.P.K. Nasanen, C.H.D. Bau, M.H. Hutz, Z. Layrisse, M.L. Petzl-Erler, L.T. Tsuneto et al.

2003 Y-chromosome evidence for differing ancient demographic histories in the Americas, The American Journal of Human Genetics 73(3), 524-539.

Brown, M.D., S.H. Hosseini, A. Torroni, H.J. Bandelt, J.C. Allen, T.G. Schurr, R. Scozzari, F. Cruciani y D.C. Wallace

1998 mtDNA haplogroup X: An ancient link between Europe/Western Asia and North America?, The American Journal of Human Genetics 63(6), 1852-1861.

Brunschön, C. y H. Behling

2009 Late Quaternary vegetation, fire and climate history reconstructed from two cores at Cerro Toledo, Podocarpus National Park, southeastern Ecuadorian Andes, Quaternary Research 72(3), 388-399.

Church, W.B.

1996 Prehistoric cultural development and interregional interaction in the tropical montane forests of Peru, tesis de doctorado, Department of Anthropology, Yale University New Haven.

Church, W.B. y A. von Hagen

2008 Chachapoyas: Cultural Development at an Andean Cloud Forest Crossroads, en: H. Silverman y W.H. Isbell (eds.), The Handbook of South American Archaeology, 906-923, Springer, New York.

Clasby, R.

2014 Exploring long term cultural developments and interregional interaction in the eastern slopes of the Andes: A case study from the site of Huayurco, Jaén Region, Peru, tesis de doctorado, Department of Anthropology,Yale University, New Haven.

Colin, R.P.

1907 El Pueblo de Huancas, Boletín de la Sociedad Geográfica de Lima XVII(XXI), 465-470.

Cook, N.D.

2010 La catástrofe demográfica andina, Peru 1520-1620, Fondo Editorial PUCP, Lima.

Dornelles, C.L., S.L. Bonatto, L.B. de Freitas y F.M. Salzano

2005 Is haplogroup X present in extant South American Indians?, American Journal of Physical Anthropology 127(4), 439-448. 


\section{Espinoza Soriano, W.}

1967 Los señoríos étnicos de Chachapoyas y la alianza hispano-chacha. Visitas, informaciones y memoriales inéditos 1572-1574, Revista Histórica Lima: Órgano de la Academia Nacional de la Historia, 224-332.

1973 Los grupos etnicos en la cuenca del río Chuquimayo siglos XV y XVI, Bulletin de l'Institut Français d'Études Andines 2(3), 19-73.

1988 Los mitmas cañar en el reino de Yaro (Pasco) siglos XV y XVI, Boletín del Instituto Riva Agüero 10, 63-82.

2006 La etnia Chilcho y su enclave de mitmas en Cajamarca, siglos xv-xx, Investigaciones Sociales 10(16), 193238.

Excoffier, L., G. Laval y S. Schneider

2005 Arlequin (version 3.0): An integrated software package for population genetics data analysis. Evolutionary Bioinformatics Online 1(EBO-1-Excoffier(Sc)), 47-50.

Forster, P., Harding, R., Torroni, A. y Bandelt, H.J.

1996 Origin and evolution of native American mtDNA variation: A reappraisal, American Journal of Human Genetics 59(4), 935-945.

Fu, Y.X.

1997 Statistical tests of neutrality of mutations against population growth, hitchhiking and background selection, Genetics 147, 915-925.

Fuselli, S., Tarazona-Santos, E., Dupanloup, I., Soto, A., Luiselli, D. y Pettener, D.

2003 Mitochondrial DNA diversity in South America and the genetic history of Andean Highlanders, Molecular Biology and Evolution 20(10), 1682-1691.

Guengerich, A.

2014 Monte Viudo: Residential and the everyday production of space in a Chachapoya community, tesis de doctorado, University of Chicago, Chicago.

2015 Settlement Organization and Architecture in Late Intermediate Period Chachapoyas, Northeastern Peru. Latin American Antiquity 26(3), 362-381.

Guffroy, J.

2006 El Horizonte corrugado: correlaciones estilísticas y culturales, Bulletin de l'Institut Français d'Études Andines 35(3), 347-359.

2008 Cultural boundaries and crossings: Ecuador and Peru, en: H. Silverman y W. Isbell (eds.), The Handbook of South American Archaeology, 906-923, Springer, New York.

von Hagen, A.

2002 Los Chachapoya y la Laguna de los Cóndores. Lima: Talleres de Grafica BIBLOS. S.A.

2004 Plumas para el rey: cazadores de aves en la Laguna de los Cóndores. SIAN, Revista Arqueológica 9(15):2425.

Hester, J.J.

1966 Late Pleistocene Environments and Early Man in South America, The American Naturalist 100(914), 377-388.

Holdridge, L.R.

1967 Life Zone Ecology. San Jose, Tropical Science Center, Costa Rica.

Horai, S., R. Kondo, Y. Nakagawa-Hattori, S. Hayashi, S. Sonoda y K. Tajima

1993 Peopling of the Americas, founded by four major lineages of mitochondrial DNA, Molecular Biology and Evolution 10(1), 23-47.

Kayser, M.

2007 Uni-parental markers in human identity testing including forensic DNA analysis, Biotechniques 43(6), $16-21$.

Kekkonen, J., M. Wikström y J.E. Brommer

2012 Heterozygosity in an isolated population of a large mammal founded by four individuals is predicted by an individual-based genetic model, PLoS ONE 7(9), e43482.

Kloss-Brandstaetter, A., D. Pacher, S. Schoenherr, H. Weissensteiner, R. Binna, G. Specht y F. Kronenberg

2010 HaploGrep: a fast and reliable algorithm for automatic classification of mitochondrial DNA haplogroups, Human Mutation 32(1), 25-32. 
Koschmieder, K.

2008 Proyecto Arqueológico Jucusbamba (Primera Temporada), informe presentado al Instituto Nacional de Cultura.

2010 Proyecto Arqueológico Jucusbamba. Segunda Temporada 2009-2010, informe presentado al Instituto Nacional de Cultura.

2012 Jucusbamba: investigaciones arqueológicas y motivos Chachapoya en el norte de la provincia de Luya,

Lerche, $\mathbf{P}$. departamento Amazonas, Perú.

1995 Los Chachapoya y los símbolos de su historia, Ediciones y Servicios Gráficos César Gayoso, Lima.

Lewis, C.M., R.Y. Tito, B. Lizárraga, B. y A.C. Stone

2005 Land, language, and loci: mtDNA in Native Americans and the genetic history of Peru, American Journal of Physical Anthropology 127(3), 351-360.

Lothrop, S.K.

1961 Early Migrations to Central and South America: An Anthropological Problem in the Light of Other Sciences, The Journal of the Royal Anthropological Institute of Great Britain and Ireland 91(1), 97-123.

Malhi, R.S., H.M. Mortensen, J.A. Eshleman, B.M. Kemp, J.G. Lorenz, F.A. Kaestle, J.R. Johnson, C. Gorodezky y D.G. Smith

2003 Native American mtDNA prehistory in the American Southwest, American Journal of Physical Anthropology 120(2), 108-124.

Medina, A.M.

1975 Las reducciones en el virreinato del Peru (1532-1580), Revista de Historia de América 80, 9-42.

Mendizabal, I., K. Sandoval, G. Berniell-Lee, F. Calafell, A. Salas, A. Martinez-Fuentes y D. Comas

2008 Genetic origin, admixture, and asymmetry in maternal and paternal human lineages in Cuba, BMC Evolutionary Biology 8(1), 213.

Nunes, D.

1992 El Descubrimiento del Amazonas (1538-1539), en: D. Ribeiro y C. Moreira (eds.), La fundación de Brasil Testimonios 1500-1700, 603, Biblioteca Ayacucho.

Nystrom, K.C.

2006 Late Chachapoya population structure prior, to Inka conquest, American Journal of Physical Anthropology 131(3), 334-342.

Olivera, Q.

1998 Evidencias arqueológicas del Período Formativo en la cuenca baja del río Utcubamba y Chinchipe, Boletín de Arqueología PUCP 2, 105-112.

2012 Proyecto de Investigación y Valoración del Patrimonio Cultural en la Zona Nor Oriental del MarañónIII Etapa, informe presentado al Ministerio de Cultura del Perú.

Perego, U.A., N. Angerhofer, M. Pala, A. Olivieri, H. Lancioni, B.H. Kashani, V. Carossa, J. E. Ekins, A. Gomez-Carballa, G. Huber et al.

2010 The initial peopling of the Americas: A growing number of founding mitochondrial genomes from Beringia, Genome Research 20(9), 1174-1179.

Pereira. L., M.J. Prata y A. Amorim

2002 Mismatch distribution analysis of Y-STR haplotypes as a tool for the evaluation of identity-by-state proportions and significance of matches-the European picture, Forensic Science International 130(2-3), $147-155$.

Quinque, D., R. Kittler, M. Kayser, M. Stoneking e I. Nasidze

2006 Evaluation of saliva as a source of human DNA for population and association studies, Analytical Biochemistry 353(2), 272-277.

Bisso-Machado, R., M. Cártira Bortolini y F.M Salzano

2012 Uniparental genetic markers in South Amerindians, Genetics and Molecular Biology 35(2), 365-387.

Reidla, M., Kivisild, T., Metspalu, E., Kaldma, K., Tambets, K., Tolk, H.V., Parik, J., Loogvali, E.L., Derenko, M., Malyarchuk, B. et al.

2003 Origin and diffusion of mtDNA haplogroup X, American Journal of Human Genetics 73(5), 1178-1190. 
Roewer, L., M. Nothnagel, L. Gusmão, V. Gomes, M. González, D. Corach, A. Sala, E. Alechine, T. Palha, N. Santos et. al.

2013 Continent-Wide Decoupling of Y-Chromosomal Genetic Variation from Language and Geography in Native South Americans, PLoS Genet 9(4), e1003460.

Rogers, A.R. y H.Harpending

1992 Population growth makes waves in the distribution of pairwise genetic differences. Molecular Biology and Evolution 9(3), 552-569.

Ruiz Estrada, A.

1972 La alfarería de Cuelap: tradición y cambio, Universidad Nacional de San Marcos, Lima.

Saignes, T.

1999 Las zonas conflictivas: fronteras iniciales de guerra, en: F. Pease y F. Moya (eds.), Historia general de America Latina: El primer contacto y la formación de nuevas sociedades, Unesco/Trotta, Lima.

Sauer, C.O.

1944 A Geographic Sketch of Early Man in America, Geographical Review 34(4), 529-573.

Schjellerup, I.

2005 Incas y españoles en la conquista de los chachapoya, Fondo Editorial PUCP/Instituto Francés de Estudios Andinos, Lima.

2008 Sacando a los caciques de la oscuridad del olvido. Etnias chachapoya y chilcho, Bulletin de l'Institut Français d'Études Andines 37(1), 111-122.

Schmitt, R., S.L. Bonatto, L.B. Freitas, V.C. Muschner, K. Hill, A.M. Hurtado y F.M. Salzano

2004 Extremely limited mitochondrial DNA variability among the Ache Natives of Paraguay, Annals of Human Biology 31(1), 87-94.

Seielstad, M.

2000 Asymmetries in the Maternal and Paternal Genetic Histories of Colombian Populations. The American Journal of Human Genetics 67(5), 1062-1066.

Slatkin, M. y Hudson, R.R.

1991 Pairwise comparisons of mitochondrial DNA sequences in stable and exponentially growing populations. Genetics 129(2), 555-562.

Tajima, F.

1989 Statistical method for testing the neutral mutation hypothesis by DNA polymorphism. Genetics 123(3), 585-595.

Tamm, E., Kivisild, T., Reidla, M., Metspalu, M., Smith, D.G., Mulligan, C.J., Bravi, C.M., Rickards, O., Martinez-Labarga C., Khusnutdinova E.K. et al.

2007 Beringian Standstill and Spread of Native American Founders. PLoS ONE 2(9), 1-6.

Tamura, K., Dudley J., Nei, M. y Kumar, S.

2007 MEGA4: Molecular Evolutionary Genetics Analysis (MEGA) Software Version 4.0. Molecular Biology and Evolution 24(8), 1596-1599.

Taylor, G.

1996 La tradición oral quechua de Chachapoyas, IFEA-ATOQ, Lima.

2000 Estudios lingüisticos sobre Chachapoyas, IFEA-UNMSM, Lima.

Torroni, A., Neel, J.V., Barrantes, R., Schurr, T.G. y Wallace, D.C.

1994 Mitochondrial-DNA clock for the Amerinds and its implications for timing their entry into NorthAmerica. Proceedings of the National Academy of Sciences of the United States of America 91(3), 1158-1162.

Torroni, A., Schurr, T.G., Cabell, M.F., Brown, M.D., Neel, J.V., Larsen, M., Smith, D,G., Vullo, C.M. y Wallace, D.C.

1993 Asian affinities and continental radiation of the four founding Native American mtDNAs. American Journal of Human Genetics 53(3), 563-590 
Torroni, A, Schurr, T.G., Yang, C.C., Szathmary, E.J.E., Williams, R.C., Schanfield, M.S., Troup, G.A, Knowler, W.C, Lawrence, D.N., Weiss, K.M. et al.

1992 Native-American mitochondrial-DNA analysis indicates that the Amerind and the NaDene populations were founded by two independent migrations. Genetics 130(1), 153-162.

Toyne, M. y Narváez, A.

2014 The Fall of Kuelap. Bioarchaeological Analysis of Death and Destruction on the Eastern Slopes of the Andes, en: A.K. Scherer y J.W. Verano (eds.), Embattled Bodies, Embattled Places War in PreColumbian Mesoamerica and the Andes, 341-364, Dumbarton Oaks Research Library and Collection, Washington D.C.

\section{Ungurahui-IWGIA O-Rd.}

2010 Peru: a chronicle of deception. Report 5. Attempts to transfer the Awajún Border Territory in the Cordillera del Cóndor to the Mining Industry, en: A. Parellada (ed.), Organization for the development of the border communities (ODECOFROC). Racimos de Ungurahui working group. International Work Group for Indigenous Affairs (IWGIA), Lima.

Uriarte, L.M. y Surrallés, A.

2007 Guía Entográfica de Alta Amazonía, IFEA, Lima.

van Oven, M. y Kayser, M.

2009 Updated comprehensive phylogenetic tree of global human mitochondrial DNA variation. Human Mutation 30(2), E386-E394.

Vázquez de Espinosa, A.

1969 Compendio y descripción de las Indias Occidentales, Ediciones Atlas, Madrid.

[1620]

Zegura S.L., Karafet, T,M,, Zhivotovsky, L.A. y Hammer, M.F.

2004 High-resolution SNPs and microsatellite haplotypes point to a single, recent entry of Native American Y chromosomes into the Americas. Molecular Biology and Evolution 21(1), 164-175.

Fecha de recepción: 30/05/2016

Fecha de aceptación: 07/02/2017 


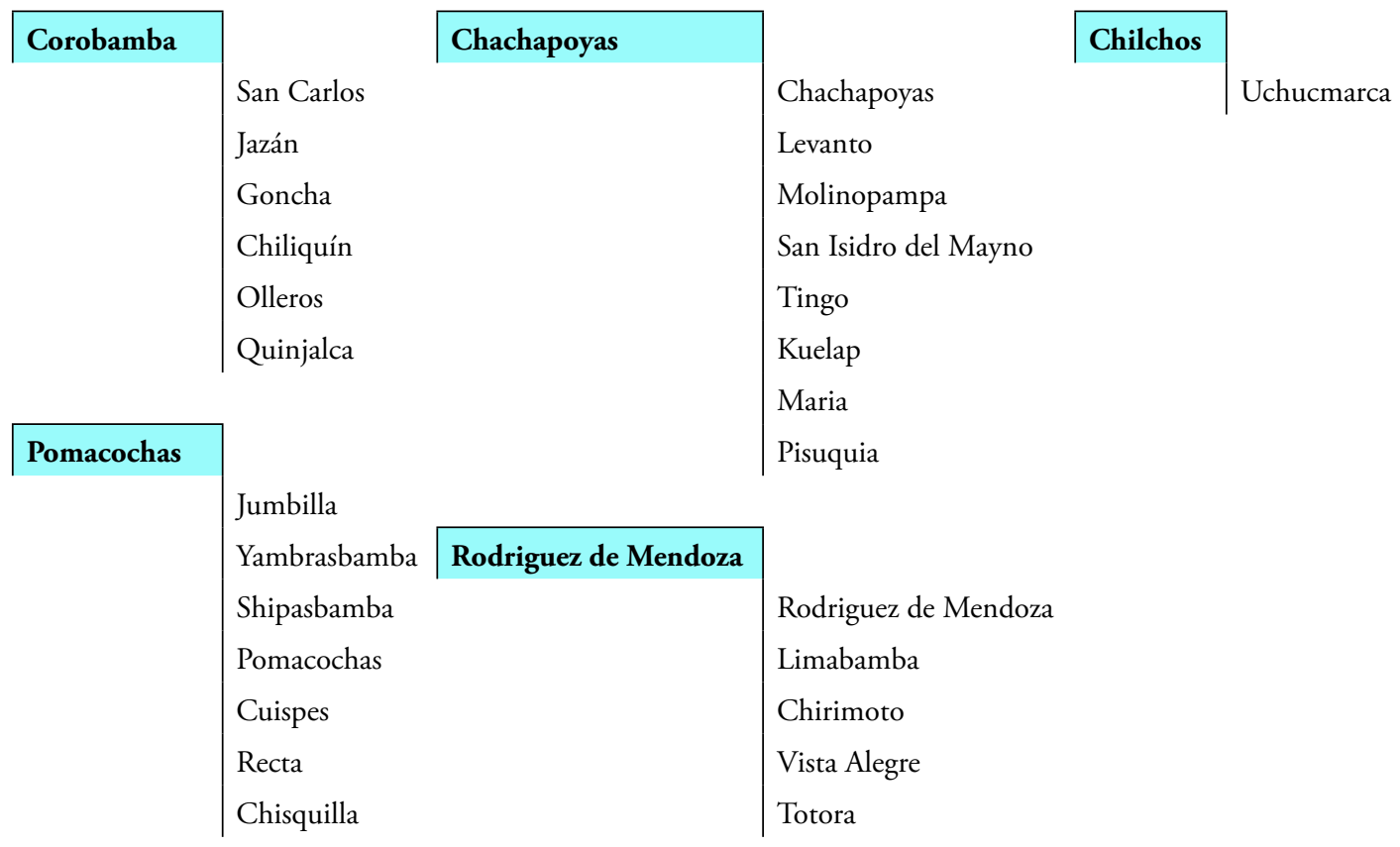

\section{Chillao}

La Jalca

Luya

Lamud

Olto

Inguilpata

Conila-

Coechán

Cuemal

Colmata

\begin{tabular}{|l|l}
\hline Leymebamba & Leymebamba \\
Dos de Mayo \\
Palmira \\
San Francisco de Yeso \\
Santo Tomás
\end{tabular}

Nota: Detalle de procedencia de muestras (lugar de nacimiento)

Tabla 1. Subunidades chachapoya considerando el lugar de nacimiento. 
Nombre, tamańo de muestra y referencia para cada marcador

\begin{tabular}{|c|c|c|c|}
\hline & \multicolumn{3}{|c|}{ mtDNA (HVR1) } \\
\hline & Población & $\mathbf{N}$ & Referencia \\
\hline 1 & Chachapoya & 276 & Este estudio \\
\hline 2 & Jivaro (Wampis y Awajún) & 47 & Este estudio \\
\hline 3 & Huancas & 21 & Este estudio \\
\hline 4 & Cajamarca & 37 & Este estudio \\
\hline 5 & Coya (Argentina) & 61 & Alvarez-Iglesias et al. 2007 \\
\hline 6 & Aymara (Perú) & 20 & Barbieri et al. 2011 \\
\hline 7 & Quechua (Perú) & 37 & Barbieri et al. 2011 \\
\hline 8 & Uros (Perú) & 7 & Barbieri et al. 2011 \\
\hline 9 & Kuna (Panamá) & 63 & Batista et al. 1995 \\
\hline 10 & Ignaciano (Bolivia) & 15 & Bert et al. 2004 \\
\hline 11 & Movima (Bolivia) & 12 & Bert et al. 2004 \\
\hline 12 & Trinitario (Bolivia) & 12 & Bert et al. 2004 \\
\hline 13 & Yuracaré (Bolivia) & 15 & Bert et al. 2004 \\
\hline 14 & Surui (Brasil) & 21 & Bonatto and Salzano 1997 \\
\hline 15 & Wai wai (Brasil) & 25 & Bonatto and Salzano 1997 \\
\hline 16 & Aymara (Piedemonte Boliviano) & 10 & Corella et al. 2007 \\
\hline 17 & Chimané (Piedemonte Boliviano) & 10 & Corella et al. 2007 \\
\hline 18 & Mosetén (Piedemonte Boliviano) & 10 & Corella et al. 2007 \\
\hline 19 & Quechua (Piedemonte Boliviano) & 16 & Corella et al. 2007 \\
\hline 20 & Ayoreo (Bolivia, Paraguay) & 91 & Dornelles et al. 2004 \\
\hline 21 & Palpa (Perú)* & 57 & Fehren-Schmitz et al. 2010 \\
\hline 22 & Arequipa (Perú) & 22 & Fuselli et al. 2003 \\
\hline 23 & San Martín (Perú) & 22 & Fuselli et al. 2003 \\
\hline 24 & Tayacaja (Perú) & 61 & Fuselli et al. 2003 \\
\hline 25 & Fueguino-Patagonia* & 24 & García-Bour et al. 2004 \\
\hline 26 & Aymara (Bolivia) & 96 & Gayà-Vidal et al. 2011 \\
\hline 27 & Quechua (Bolivia) & 93 & Gayà-Vidal et al. 2011 \\
\hline 28 & Cheyenne (USA) & 39 & Kittles et al. 1999 \\
\hline 29 & Ngöebe (Panamá) & 46 & Kolman et al. 1995 \\
\hline 30 & Embera (Panamá) & 44 & Kolman and Bermingham 1997 \\
\hline 31 & Wounan (Panamá) & 31 & Kolman and Bermingham 1997 \\
\hline 32 & Ancash (Perú) & 33 & Lewis et al. 2007 \\
\hline 33 & Tupe (Perú) & 17 & Lewis et al. 2007 \\
\hline 34 & Yungay (Perú) & 38 & Lewis et al. 2007 \\
\hline 35 & Athapaskan (USA) & 13 & Malhi et al. 2003 \\
\hline 36 & Pueblo (USA) & 13 & Malhi et al. 2003 \\
\hline 37 & Pima Superior (USA) & 9 & Malhi et al. 2003 \\
\hline 38 & Uto-Azteca (USA) & 5 & Malhi et al. 2003 \\
\hline 39 & Yuman (USA) & 14 & Malhi et al. 2003 \\
\hline 40 & Guaraní (Brasil) & 202 & Marrero et al. 2007 \\
\hline 41 & Kaingang (Brasil) & 78 & Marrero et al. 2007 \\
\hline 42 & Apalaí (Brasil) & 102 & Mazieres et al. 2008 \\
\hline 43 & Emerillon (Guyana Francesa) & 30 & Mazieres et al. 2008 \\
\hline 44 & Kalina (Guyana Francesa) & 27 & Mazieres et al. 2008 \\
\hline 45 & Matsiguenga (Perú) & 38 & Mazieres et al. 2008 \\
\hline 46 & Palikur (Guyana Francesa) & 48 & Mazieres et al. 2008 \\
\hline 47 & Wayampi (Brasil) & 53 & Mazieres et al. 2008 \\
\hline 48 & Chibchan Arsario (Colombia) & 20 & Melton et al. 2007 \\
\hline 49 & Chibchan Ijka (Colombia) & 31 & Melton et al. 2007 \\
\hline 50 & Chibchan Kogi (Colombia) & 21 & Melton et al. 2007 \\
\hline 51 & Arawak Wayuú (Colombia) & 30 & Melton et al. 2017 \\
\hline 52 & Mapuche Huapi (Chile) & 34 & Moraga et al. 2000 \\
\hline 53 & Pehuenche (Chile) & 23 & Moraga et al. 2000 \\
\hline 54 & Norte de Chile* & 26 & Moraga et al. 2005 \\
\hline 55 & Cayapa (Ecuador) & 120 & Rickards et al. 1999 \\
\hline 56 & Mbyá-Guaraní (Argentina) & 121 & Sala et al. 2010 \\
\hline 57 & El Salvador & 90 & Salas et al. 2008 \\
\hline 58 & Huetar (Costa Rica) & 27 & Santos et al. 1994 \\
\hline 59 & Aché (Paraguay) & 63 & Schmitt et al. 2004 \\
\hline 60 & Sicán $($ Perú)* & 28 & Shimada et al. 2004 \\
\hline 61 & Cuzco (Perú)* & 35 & Shinoda et al. 2006 \\
\hline 62 & Formativo Ilo (Perú)* & 15 & Shinoda et al. 2010 \\
\hline 63 & Chiribaya LIP (Perú)* & 27 & Shinoda et al. 2010 \\
\hline 64 & Pre-contacto (Mexico)* & 27 & Solorzano 2006 \\
\hline 65 & Contacto $($ Mexico)* & 26 & Solorzano 2006 \\
\hline 66 & Post-contacto (Mexico)* & 25 & Solorzano 2006 \\
\hline 67 & Apache (USA) & 20 & Tamm et al. 2007 \\
\hline 68 & Arsario (Colombia) & 47 & Tamm et al. 2007 \\
\hline 69 & Catamarca (Argentina) & 25 & Tamm et al. 2007 \\
\hline 70 & Coreguajé (Colombia) & 27 & Tamm et al. 2007 \\
\hline 71 & Dogrib (Canada) & 23 & Tamm et al. 2007 \\
\hline 72 & Salta (Argentina) & 18 & Tamm et al. 2007 \\
\hline 73 & Este de Colombia & 21 & Torres et al. 2006 \\
\hline 74 & Sur de Colombia & 23 & Torres et al. 2006 \\
\hline 75 & Oeste de Colombia & 15 & Torres et al. 2006 \\
\hline 76 & Guahibo (Venezuela) & 59 & Vona et al. 2005 \\
\hline 77 & Bella Coola (Canada) & 40 & Ward et al. 1993 \\
\hline 78 & Gaviâo (Brasil) & 27 & Ward et al. 1996 \\
\hline 79 & Xavante (Brasil) & 25 & Ward et al. 1996 \\
\hline 80 & Zoró (Brasil) & 29 & Ward et al. 1996 \\
\hline
\end{tabular}

\begin{tabular}{|c|c|c|}
\hline \multicolumn{3}{|c|}{ Y-STRs } \\
\hline Población & $\mathbf{N}$ & Referencia \\
\hline Chachapoya & 113 & Este estudio \\
\hline Jivaro (Wampis y Awajún) & 24 & Este estudio \\
\hline Huancas & 12 & Este estudio \\
\hline Cajamarca & 25 & Este estudio \\
\hline Embera (Panamá) & 17 & Ascunce et al. 2008 \\
\hline Kuna (Panamá) & 18 & Ascunce et al. 2008 \\
\hline Ngöebe (Panamá) & 26 & Ascunce et al. 2008 \\
\hline Wounan (Panamá) & 16 & Ascunce et al. 2008 \\
\hline Colla (Argentina) & 14 & Blanco-Verea et al. 2010 \\
\hline Chippewa Wisconsin (USA) & 12 & Bolnick et al. 2006 \\
\hline Chippewa Sioux (USA) & 24 & Bolnick et al. 2006 \\
\hline Oklahoma (USA) & 15 & Bolnick et al. 2006 \\
\hline Athabaskan (Alaska) & 23 & Davis et al. 2011 \\
\hline Aymara (Bolivia) & 59 & Gayà-Vidal et al. 2011 \\
\hline Quechua (Bolivia) & 55 & Gayà-Vidal et al. 2011 \\
\hline Waorani (Ecuador) & 39 & González Andrade et al. 2007 \\
\hline Peruvian & 78 & Iannacone et al. 2005 \\
\hline Rio Grande do Sul (Brasil) & 203 & Leite et al. 2008 \\
\hline Maya Qeqchi (Guatemala) & 11 & Martínez-González et al.2012 \\
\hline Maya Mam (Guatemala) & 13 & Martínez-González et al.2012 \\
\hline Maya Kiche (Guatemala) & 16 & Martínez-González et al.2012 \\
\hline Maya Kaqchiquel (Guatemala) & 13 & Martínez -González et al.2012 \\
\hline Awa-Guaja (Brasil) & 46 & Palha et al. 2010 \\
\hline Parakana (Brasil) & 38 & Palha et al. 2010 \\
\hline Tiriyó (Brasil) & 35 & Palha et al. 2010 \\
\hline Urubu-Kaapor (Brasil) & 27 & Palha et al. 2010 \\
\hline Waiāpi (Brasil) & 13 & Palha et al. 2010 \\
\hline Zoé (Brasil) & 25 & Palha et al. 2010 \\
\hline Arara (Brasil) & 20 & Roewer et al. 2013 \\
\hline Arequipa (Perú) & 16 & Roewer et al. 2013 \\
\hline Asurini (Brasil) & 15 & Roewer et al. 2013 \\
\hline BariBoxi (Brasil) & 16 & Roewer et al. 2013 \\
\hline Cauca-Narińo-Chocó (Colombia) & 31 & Roewer et al. 2013 \\
\hline Cuzco (Perú) & 10 & Roewer et al. 2013 \\
\hline Embera Chamí (Colombia) & 24 & Roewer et al. 2013 \\
\hline Gaviáo (Brasil) & 18 & Roewer et al. 2013 \\
\hline Guaraní (Argentina) & 76 & Roewer et al. 2013 \\
\hline Ipixuna (Brasil) & 21 & Roewer et al. 2013 \\
\hline Junín (Perú) & 13 & Roewer et al. 2013 \\
\hline Karitiana (Brasil) & 16 & Roewer et al. 2013 \\
\hline Kayapo (Brasil) & 16 & Roewer et al. 2013 \\
\hline Kichwa Pastaza (Ecuador) & 42 & Roewer et al. 2013 \\
\hline Lecos (Bolivia) & 11 & Roewer et al. 2013 \\
\hline Mapuche (Chile) & 49 & Roewer et al. 2013 \\
\hline Mojeńos (Bolivia) & 15 & Roewer et al. 2013 \\
\hline Mosetén (Bolivia) & 11 & Roewer et al. 2013 \\
\hline Pilagá (Argentina) & 65 & Roewer et al. 2013 \\
\hline Tehuelche (Argentina) & 10 & Roewer et al. 2013 \\
\hline Terena (Brasil) & 32 & Roewer et al. 2013 \\
\hline Shipibo Conibo (Perú) & 21 & Roewer et al. 2013 \\
\hline Wayuu (Colombia) & 19 & Roewer et al. 2013 \\
\hline Wichi (Argentina) & 45 & Roewer et al. 2013 \\
\hline Yanomami (Brasil) & 10 & Roewer et al. 2013 \\
\hline Beni (Bolivia) & 63 & Tirado et al. 2009 \\
\hline Toba (Argentina) & 90 & Toscanini et al. 2008 \\
\hline
\end{tabular}

\section{* Muestras antiguas}

Poblaciones de este estudio en negrita 
1 Alvarez-Iglesias V, Jaime JC, Carracedo A, and Salas A. 2007. Coding region mitochondrial DNA SNPs: Targeting East Asian and Native American haplogroups. Forensic Science International-Genetics 1(1):44-55.

2 Ascunce MS, González-Oliver A, and Mulligan CJ. 2008. Y-Chromosome Variability in Four Native American Populations from Panamá. Human Biology 80(3):287-302.

3 Barbieri C, Heggarty P, Castrì L, Luiselli D, and Pettener D. 2011. Mitochondrial DNA variability in the Titicaca basin: Matches and mismatches with linguistics and ethnohistory. American Journal of Human Biology 23(1):89-99.

4 Batista O, Kolman CJ, and Bermingham E. 1995. Mitochondrial DNA diversity in the Kuna amerinds of Panamá. Human Molecular Genetics 4(5):921-929.

5 Bert F, Corella A, Gené M, Pérez-Pérez A, and Turbón D. 2004. Mitochondrial DNA diversity in the Llanos de Moxos: Moxo, Movima and Yuracare Amerindian populations from Bolivia lowlands. Annals of Human Biology 31(1):9-28.

6 Blanco-Verea A, Jaime JC, Brión M, and Carracedo A. 2010. Y-chromosome lineages in native South American population. Forensic Science International: Genetics 4(3):187-193.

7 Bolnick DA, Bolnick DI, and Smith DG. 2006. Asymmetric Male and Female Genetic Histories among Native Americans from Eastern North America. Molecular Biology and Evolution 23(11):2161-2174

8 Bonatto SL, and Salzano FM. 1997. A single and early migration for the peopling of the Americas supported by mitochondrial DNA sequence data. Proceedings of the National Academy of Sciences 94(5):1866-1871.

9 Corella A, Bert F, Pérez-Pérez A, Gen M, and Turbón D. 2007. Mitochondrial DNA diversity of the Amerindian populations living in the Andean Piedmont of Bolivia: Chimane, Moseten, Aymara and Quechua. Annals of Human Biology 34(1):34-55.

10 Davis C, Ge J, Chidambaram A, King J, Turnbough M, Collins M, Dym O, Chakraborty R, Eisenberg A, and Budowle B. 2011. Y-STR loci diversity in native Alaskan populations. International Journal of Legal Medicine 125(4):559-563.

11 Dornelles CL, Battilana J, Fagundes NJR, Freitas LB, Bonatto SL, and Salzano FM. 2004. Mitochondrial DNA and Alu insertions in a genetically peculiar population: The ayoreo Indians of Bolivia and Paraguay. American Journal of Human Biology 16(4):479-488.

12 Fehren-Schmitz L, Reindel M, Cagigao ET, Hummel S, and Herrmann B. 2010. Pre-Columbian population dynamics in coastal southern Perú: A diachronic investigation of mtDNA patterns in the Palpa region by ancient DNA analysis. Am J Phys Anthropol 141(2):208-221.

13 Fuselli S, Tarazona-Santos E, Dupanloup I, Soto A, Luiselli D, and Pettener D. 2003. Mitochondrial DNA Diversity in South America and the Genetic History of Andean Highlanders. Molecular Biology and Evolution 20(10):1682-1691

14 Garcia-Bour J, Perez-Perez A, Alvarez S, Fernandez E, Lopez-Parra AM, Arroyo-Pardo E, and Turbon D. 2004. Early population differentiation in extinct aborigines from Tierra del Fuego-Patagonia: Ancient mtDNA sequences and Y-chromosome STIR characterization. Am J Phys Anthropol 123(4):361-370.

15 Gayà-Vidal M, Moral P, Saenz-Ruales N, Gerbault P, Tonasso L, Villena M Vasquez R, Bravi CM, and Dugoujon J-M. 2011. mtDNA and Y-chromosome diversity in Aymaras and Quechuas from Bolivia: Different stories and special genetic traits of the Andean Altiplano populations. Am J Phys Anthropol 145(2):215-230.

16 González Andrade JF. 2006. Análisis molecular de variación de polimorfismos STR autosómicos y de cromosoma "y" en grupos étnicos de Ecuador con aplicación médico forense. España: Universidad de Zaragoza. 274 p.

17 Iannacone GC, Tito RY, Lopez PW, Medina ME, and Lizarraga B. 2005. Y-chromosomal Haplotypes for the PowerPlex (R) Y for twelve STRs in Perúvian population sample. Journal of Forensic Sciences 50(1):239-242.

18 Kittles RA, Bergen AW, Urbanek M, Virkkunen M, Linnoila M, Goldman D, and Long JC. 1999. Autosomal, mitochondrial, and Y chromosome DNA variation in Finland: Evidence for a male-specific bottleneck. Am J Phys Anthropol 108(4):381-399.

19 Kolman CJ, and Bermingham E. 1997. Mitochondrial and Nuclear DNA Diversity in the Chocó and Chibcha Amerinds of Panamá. Genetics 147(3):1289-1302

20 Kolman CJ, Bermingham E, Cooke R, Ward RH, Arias TD, and Guionneau-Sinclair F. 1995. Reduced mtDNA diversity in the Ngöbé Amerinds of Panamá. Genetics 140(1):275-283.

21 Leite FPN, Callegari-Jacques SM, Carvalho BA, Kommers T, Matte CHF, Raimann PE, Schwengber SP, Sortica VA, Tsuneto LT, Petzl-Erler ML et al. 2008. Y-STR analysis in Brasilian and South Amerindian populations. American Journal of Human Biology 20(3):359-363.

22 Lewis Jr CM, Lizárraga B, Tito RY, López PW, Iannacone GC, Medina A, Martínez R, Polo SI, De La Cruz AF, Cáceres AM et al. . 2007. Mitochondrial DNA and the Peopling of South America. Human Biology 79(2):159-178.

23 Malhi RS, Mortensen HM, Eshleman JA, Kemp BM, Lorenz JG, Kaestle FA, Johnson JR, Gorodezky C, and Smith DG. 2003. Native American mtDNA prehistory in the American Southwest. Am J Phys Anthropol 120(2):108-124.

24 Marrero AR, Silva-Junior WA, Bravi CM, Hutz MH, Petzl-Erler ML, Ruiz-Linares A, Salzano FM, and Bortolini MC. 2007. Demographic and evolutionary trajectories of the Guarani and Kaingang natives of Brasil. Am J Phys Anthropol 132(2):301-310.
25 Martínez-González LJ, Saiz M, Álvarez-Cubero MJ, Gómez-Martín A, Álvarez JC, Martínez-Labarga C, and Lorente JA. 2012. Distribution of Y chromosomal STRs loci in Mayan and Mestizo populations from Guatemala. Forensic Science International: Genetics 6(1):136-142.

26 Mazieres S, Guitard E, Crubezy E, Dugoujon JM, Bortolini MC, Bonatto SL, Hutz MH, Bois E, Tiouka F, Larrouy G et al. . 2008. Uniparenta (mtDNA, Y-chromosome) polymorphisms in French Guiana and two related populations - Implications for the region's colonization. Annals of Human populations - Implica

27 Melton PE, Briceño I, Gómez A, Devor EJ, Bernal JE, and Crawford MH. 2007. Biological relationship between central and South American Chibchan speaking populations: Evidence from mtDNA. Am J Phys Anthropol 133(1):753-770.

28 Moraga M, Santoro CM, Standen VG, Carvallo P, and Rothhammer F 2005. Microevolution in prehistoric Andean populations: Chronologic mtDNA variation in the desert valleys of northern Chile. Am J Phys Anthropol 127(2):170-181.

29 Moraga ML, Rocco P, Miquel JF, Nervi F, Llop E, Chakraborty R, Rothhammer F, and Carvallo P. 2000. Mitochondrial DNA polymorphisms in Chilean aboriginal populations: Implications for the peopling of the southern cone of the continent. Am J Phys Anthropol 113(1):19-29.

30 Palha TJBF, Rodrigues EMR, and dos Santos SEB. 2010. Y-STR haplotypes of Native American populations from the Brasilian Amazon region. Forensic Science International: Genetics 4(5):e121-e123.

31 Rickards O, Martínez-Labarga C, Lum JK, De Stefano GF, and Cann RL. 1999. mtDNA History of the Cayapa Amerinds of Ecuador: Detection of Additional Founding Lineages for the Native American Populations. The American Journal of Human Genetics 65(2):519-530.

32 Roewer L, Nothnagel M, Gusmão L, Gomes V, González M, Corach D, Sala A, Alechine E, Palha T, Santos N et al. . 2013. Continent-Wide Decoupling of Y-Chromosomal Genetic Variation from Language and Geography in Native South Americans. PLoS Genet 9(4):e1003460.

33 Sala A, Argueelles CF, Marino ME, Bobillo C, Fenocchio A, and Corach D. 2010. Genetic Analysis of Six Communities of Mbya-Guarani Inhabiting Northeastern Argentina by Means of Nuclear and Mitochondrial Polymorphic Markers. Human Biology 82(4):433-456.

34 Salas A, Acosta A, Álvarez-Iglesias V, Cerezo M, Phillips C, Lareu MV, and Carracedo Á. 2008. The mtDNA ancestry of admixed Colombian populations. American Journal of Human Biology 20(5):584-591.

35 Santos M, Ward RH, and Barrantes R. 1994. MtDNA variation in the Chibcha amerindian Huetar from Costa Rica. Human Biology 66(6):963977

36 Schmitt R, Bonatto SL, Freitas LB, Muschner VC, Hill K, Hurtado AM, and Salzano FM. 2004. Extremely limited mitochondrial DNA variability among the Ache Natives of Paraguay. Annals of Human Biology 31(1):87-94.

37 Shimada I, Shinoda K, Farnum J, Corruccini R, and Watanabe H. 2004. An integrated analysis of pre-Hispanic mortuary practices - A Middle Sican case study. Current Anthropology 45(3):369-402.

38 Shinoda K-i, Adachi N, Guillen S, and Shimada I. 2006. Mitochondrial DNA analysis of ancient Perúvian highlanders. Am J Phys Anthropol 131(1):98-107.

39 Shinoda K, Guillen S, and Shimada I. 2010. Population history of the Moquegua valley, far South Coast of Perú. In: Auerbach BM, editor. Human Variation in the Americas The Integration of Archaeology and Biological Anthropology. USA: Center for Archaeological Investigations. p 238-259.

40 Solórzano Navarro E. 2006. De la Mesoamerica prehispánica a la colonial: la huella del ADN antiguo. Barcelona, España: Universidad Autónoma de Barcelona. $225 \mathrm{p}$.

41 Tamm E, Kivisild T, Reidla M, Metspalu M, Smith DG, Mulligan CJ, Bravi CM, Rickards O, Martinez-Labarga C, Khusnutdinova EK et al. . 2007. Beringian Standstill and Spread of Native American Founders. PLoS ONE 2(9).

42 Tirado M, López-Parra AMa, Baeza C, Bert F, Corella A, Pérez-Pérez A, Turbón D, and Arroyo-Pardo E. 2009. Y-chromosome haplotypes defined by 17 STRs included in AmpFISTR Yfiler PCR Amplification Kit in a mult ethnical population from El Beni Department (North Bolivia). Legal Medicine 11(2):101-103.

43 Torres MM, Bravi CM, Bortolini MC, Duque C, Callegari-Jacques S, Ortiz D, Bedoya G, De Restrepo HG, and Ruiz-Linares A. 2006. A revertant of the major founder native American haplogroup $\mathrm{C}$ common in populations from northern South America. American Journal of Human Biology 18(1):59-65.

44 Toscanini U, Gusmáo L, Berardi G, Amorim A, Carracedo Á, Salas A, and Raimondi E. 2008. Y chromosome microsatellite genetic variation in two Native American populations from Argentina: Population stratification and mutation data. Forensic Science International: Genetics 2(4):274-280.

45 Ward RH, Redd A, Valencia D, Frazier B, and Pääbo S. 1993. Genetic and linguistic differentiation in the Americas. Proceedings of the National Academy of Sciences 90(22):10663-10667.

46 Ward RH, Salzano FM, Bonatto SL, Hutz MH, Coimbra CEA, and Santos RV. 1996. Mitochondrial DNA polymorphism in three Brasilian Indian tribes. American Journal of Human Biology 8(3):317-323.

47 Vona G, Falchi A, Moral P, Calò CM, and Varesi L. 2005. Mitochondrial sequence variation in the Guahibo Amerindian population from Venezuela. Am J Phys Anthropol 127(3):361-369. 
Indices de diversidad mitocondrial (ADN mitocondrial)

\begin{tabular}{|c|c|c|c|c|c|c|c|c|c|}
\hline Población & $\mathbf{N}$ & $A$ & $H$ & $S D H$ & $\pi$ & $S D \pi$ & $M N P D$ & SDMNPD & $h r$ (HVSI) \\
\hline Chachapoya & 245 & 149 & 0.9759 & 0.0051 & 0.016005 & 0.008124 & 10.003297 & 4.589423 & 12.511 \\
\hline Jivaro & 46 & 34 & 0.9797 & 0.0105 & 0.012823 & 0.006735 & 8.014116 & 3.791601 & 12.129 \\
\hline Huancas & 21 & 16 & 0.9571 & 0.0319 & 0.016817 & 0.008914 & 10.510918 & 4.990734 & 9.714 \\
\hline Cajamarca & 34 & 27 & 0.9857 & 0.0108 & 0.014333 & 0.007527 & 8.958238 & 4.230781 & 12.461 \\
\hline Dogrib & 23 & 8 & 0.5257 & 0.1262 & 0.005159 & 0.003433 & 1.826453 & 1.089845 & 3.715 \\
\hline Bella Coola & 40 & 11 & 0.9038 & 0.0203 & 0.016839 & 0.009218 & 5.337922 & 2.630545 & 7.927 \\
\hline Cheyenne & 39 & 24 & 0.9649 & 0.0137 & 0.025608 & 0.013492 & 8.117879 & 3.849663 & 10.640 \\
\hline Athapaskan & 13 & 8 & 0.8974 & 0.0666 & 0.016502 & 0.009215 & 8.052995 & 4.000543 & n.o. \\
\hline Pueblo & 13 & 7 & 0.8718 & 0.0670 & 0.005275 & 0.003397 & 2.574306 & 1.474622 & n.o. \\
\hline Apache & 20 & 11 & 0.8684 & 0.0640 & 0.021059 & 0.011472 & 7.454736 & 3.636295 & n.o. \\
\hline Yuman \& Pima & 23 & 17 & 0.9644 & 0.0258 & 0.014484 & 0.007869 & 7.068215 & 3.443454 & n.o. \\
\hline Mexico* & 78 & 39 & 0.9264 & 0.0217 & 0.024533 & 0.013453 & 4.710341 & 2.330817 & n.o. \\
\hline El Salvador & 90 & 54 & 0.8956 & 0.0305 & 0.007311 & 0.004151 & 3.582152 & 1.836099 & 10.292 \\
\hline Huetar & 27 & 27 & 1.0000 & 0.0101 & 0.011859 & 0.006872 & 3.759388 & 1.956005 & 4.210 \\
\hline Ngöebe & 46 & 11 & 0.6329 & 0.0664 & 0.014333 & 0.007968 & 4.543530 & 2.275230 & 2.869 \\
\hline Kuna & 63 & 38 & 0.9042 & 0.0326 & 0.012235 & 0.006902 & 3.878366 & 1.973235 & 2.227 \\
\hline Wounan & 31 & 28 & 0.9935 & 0.0100 & 0.025458 & 0.013514 & 8.070092 & 3.850714 & 10.030 \\
\hline Embera & 44 & 36 & 0.9905 & 0.0071 & 0.022084 & 0.011743 & 7.000692 & 3.352497 & 8.316 \\
\hline Arawak Wayuu & 30 & 5 & 0.7885 & 0.0263 & 0.020755 & 0.011166 & 6.973702 & 3.371353 & 3.666 \\
\hline Chibcha Kogi & 21 & 3 & 0.5238 & 0.1055 & 0.011323 & 0.006626 & 3.804548 & 1.994390 & 2.000 \\
\hline Chibcha Arsario & 20 & 3 & 0.6474 & 0.0565 & 0.014972 & 0.008477 & 5.030436 & 2.550320 & n.o. \\
\hline Chibcha Ijka & 31 & 3 & 0.1849 & 0.0905 & 0.005090 & 0.003398 & 1.710205 & 1.026198 & 1.527 \\
\hline Arsario & 47 & 33 & 0.9029 & 0.0412 & 0.013817 & 0.007609 & 4.891099 & 2.426655 & 3.670 \\
\hline Kalina & 27 & 13 & 0.9316 & 0.0236 & 0.022811 & 0.012223 & 7.664646 & 3.687670 & 9.706 \\
\hline Palikur & 48 & 10 & 0.8076 & 0.0340 & 0.014516 & 0.007993 & 4.877326 & 2.419714 & 5.385 \\
\hline Emerillon & 30 & 4 & 0.5241 & 0.0737 & 0.011264 & 0.006495 & 3.784618 & 1.961007 & 2.333 \\
\hline Wayampi & 53 & 12 & 0.8824 & 0.0217 & 0.022627 & 0.011899 & 7.602556 & 3.603375 & 6.871 \\
\hline Apalaí & 102 & 16 & 0.8715 & 0.0174 & 0.021229 & 0.011119 & 7.132786 & 3.373192 & 5.937 \\
\hline Wai wai & 25 & 11 & 0.8333 & 0.0543 & 0.024811 & 0.013310 & 7.865175 & 3.786100 & 6.329 \\
\hline Guahibo & 59 & 27 & 0.9158 & 0.0204 & 0.018180 & 0.009789 & 5.763043 & 2.797821 & 5.302 \\
\hline Colombia (este \& oeste) & 36 & 23 & 0.9333 & 0.0325 & 0.020574 & 0.011011 & 6.912867 & 3.328516 & n.o. \\
\hline Colombia (sur) & 23 & 10 & 0.8300 & 0.0562 & 0.010999 & 0.006434 & 3.695764 & 1.938374 & 7.075 \\
\hline Coreguajé & 27 & 18 & 0.9430 & 0.0318 & 0.017938 & 0.009773 & 6.350130 & 3.106378 & 7.572 \\
\hline Cayapa & 120 & 13 & 0.7766 & 0.0274 & 0.017334 & 0.009241 & 5.824223 & 2.804158 & 3.919 \\
\hline Sicán* & 28 & 17 & 0.9550 & 0.0203 & 0.018118 & 0.009897 & 6.087757 & 2.986787 & 7.437 \\
\hline Yungay & 38 & 29 & 0.9744 & 0.0151 & 0.019963 & 0.010755 & 6.328319 & 3.068149 & 9.434 \\
\hline Ancash & 33 & 30 & 0.9924 & 0.0104 & 0.021745 & 0.011672 & 6.893083 & 3.327073 & 13.710 \\
\hline Matsiguenga & 38 & 11 & 0.7767 & 0.0544 & 0.008393 & 0.005031 & 2.820083 & 1.521271 & 6.074 \\
\hline San Martin & 22 & 15 & 0.9394 & 0.0367 & 0.017927 & 0.009908 & 6.023593 & 2.983746 & 10.268 \\
\hline Tayacaja & 61 & 42 & 0.9678 & 0.0144 & 0.021151 & 0.011158 & 7.106791 & 3.380603 & 13.160 \\
\hline Tupe & 17 & 13 & 0.9265 & 0.0579 & 0.020347 & 0.011339 & 6.449942 & 3.211958 & n.o. \\
\hline Palpa* & 57 & 54 & 0.9981 & 0.0037 & 0.016406 & 0.008766 & 6.267217 & 3.018737 & 13.569 \\
\hline Arequipa & 22 & 18 & 0.9784 & 0.0213 & 0.016464 & 0.009179 & 5.531994 & 2.764291 & 12.082 \\
\hline Formativo-Ilo* & 14 & 12 & 0.9670 & 0.0437 & 0.011116 & 0.006698 & 3.734923 & 2.004785 & n.o. \\
\hline Chiribaya-Ilo* & 27 & 19 & 0.9573 & 0.0257 & 0.013657 & 0.007707 & 4.588807 & 2.325376 & 4.210 \\
\hline Cuzco* & 35 & 21 & 0.9244 & 0.0311 & 0.024751 & 0.013767 & 4.801779 & 2.402416 & n.o. \\
\hline Quechua (Peru\&Bolivia) anc & 137 & 81 & 0.9816 & 0.0052 & 0.018542 & 0.009765 & 6.526718 & 3.104896 & n.o. \\
\hline Aymara (Perú) & 20 & 14 & 0.9474 & 0.0344 & 0.008887 & 0.005370 & 3.128089 & 1.692449 & n.o. \\
\hline Aymara (Bolivia) & 96 & 61 & 0.9875 & 0.0036 & 0.010159 & 0.005457 & 5.526349 & 2.680027 & 11.829 \\
\hline Quechua \& Aymara (Pieden & 26 & 25 & 0.9969 & 0.0117 & 0.010177 & 0.005989 & 3.419430 & 1.806315 & n.o. \\
\hline Chimané \& Mosetén (Pied€ & 20 & 15 & 0.9632 & 0.0282 & 0.019822 & 0.010906 & 6.660329 & 3.280901 & n.o. \\
\hline Ignaciano \& Movima \& Trin & 39 & 25 & 0.9406 & 0.0280 & 0.018444 & 0.009949 & 6.197048 & 3.008847 & n.o. \\
\hline Yuracaré & 15 & 13 & 0.9810 & 0.0308 & 0.021960 & 0.012203 & 7.378602 & 3.656797 & n.o. \\
\hline Ayoreo & 91 & 8 & 0.4733 & 0.0608 & 0.008156 & 0.004836 & 2.740475 & 1.466803 & 2.166 \\
\hline Gavião & 27 & 13 & 0.9031 & 0.0331 & 0.015764 & 0.008807 & 4.997177 & 2.506774 & 4.726 \\
\hline Zoro & 29 & 8 & 0.7586 & 0.0661 & 0.013172 & 0.007444 & 4.438992 & 2.253782 & 5.244 \\
\hline Xavante & 25 & 4 & 0.6767 & 0.0528 & 0.010218 & 0.006019 & 3.433093 & 1.814842 & 2.800 \\
\hline Surui & 21 & 20 & 0.9952 & 0.0165 & 0.003750 & 0.002793 & 1.188836 & 0.793033 & 1.952 \\
\hline Norte de Chile* & 26 & 25 & 0.9969 & 0.0117 & 0.018767 & 0.010179 & 6.774821 & 3.298389 & 17.100 \\
\hline Coya-Argentina & 61 & 57 & 0.9973 & 0.0038 & 0.014981 & 0.007881 & 7.340463 & 3.482065 & 13.493 \\
\hline Salta & 18 & 15 & 0.9739 & 0.0293 & 0.017787 & 0.009899 & 6.296738 & 3.133601 & n.o. \\
\hline Catamarca & 25 & 11 & 0.8767 & 0.0401 & 0.016296 & 0.008992 & 5.768709 & 2.856287 & 7.162 \\
\hline Aché & 63 & 3 & 0.2038 & 0.0639 & 0.003650 & 0.002607 & 1.226396 & 0.789942 & 0.910 \\
\hline Kaingang & 78 & 12 & 0.7729 & 0.0320 & 0.022736 & 0.011876 & 7.639143 & 3.600871 & 5.039 \\
\hline Guaraní & 202 & 11 & 0.7682 & 0.0205 & 0.008538 & 0.004992 & 2.868764 & 1.515690 & 4.149 \\
\hline Mbyà-Guaraní & 121 & 17 & 0.7963 & 0.0238 & 0.013958 & 0.007622 & 4.689844 & 2.313105 & 4.580 \\
\hline Mapuche \& Pehuenche & 57 & 20 & 0.8709 & 0.0367 & 0.018450 & 0.009868 & 6.199299 & 2.989178 & n.o. \\
\hline Fueguino-Patagonia* & 24 & 16 & 0.9167 & 0.0482 & 0.014331 & 0.008081 & 4.815051 & 2.435693 & 4.476 \\
\hline
\end{tabular}

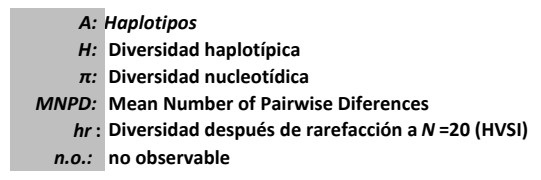

Poblaciones de estudio en negrita

* Muestras antiguas

Tabla S3. Indices de diversidad y diversidad genética después de rarefacción a $N=20$ 
Indices de diversidad para Cromosoma Y (9 loci)

\begin{tabular}{|c|c|c|c|c|c|c|c|c|c|c|}
\hline & Población & $\mathbf{N}$ & $A$ & $H$ & SDH & Hd loci & SD Hd loci & MNPD & SDMNPD & $h r$ \\
\hline 1 & Chachapoya & 68 & 47 & 0.9833 & 0.0066 & 0.530875 & 0.290882 & 4.777875 & 2.361316 & 17.554 \\
\hline 2 & Jivaro & 23 & 13 & 0.8972 & 0.0503 & 0.451471 & 0.259821 & 4.063241 & 2.096258 & 13.162 \\
\hline 3 & Huancas & 10 & 7 & 0.9111 & 0.0773 & 0.449383 & 0.274847 & 4.044444 & 2.186735 & n.o. \\
\hline 4 & Cajamarca & 11 & 11 & 1.0000 & 0.0388 & 0.561616 & 0.330762 & 5.054545 & 2.638923 & n.o. \\
\hline 5 & Athabaskan & 23 & 10 & 0.9368 & 0.0210 & 0.657883 & 0.362206 & 5.920949 & 2.923090 & 8.915 \\
\hline 6 & Chippewa Wisconsin & 12 & 10 & 0.9697 & 0.0443 & 0.602694 & 0.349267 & 5.424242 & 2.792229 & n.o. \\
\hline 7 & Chippewa Sioux & 24 & 10 & 0.9348 & 0.0202 & 0.608696 & 0.337237 & 5.478261 & 2.722514 & n.o. \\
\hline 8 & Oklahoma & 15 & 8 & 0.9143 & 0.0425 & 0.440212 & 0.260402 & 3.961905 & 2.089565 & n.o. \\
\hline 9 & Qeqchi (Maya) & 11 & 9 & 0.9636 & 0.0510 & 0.444444 & 0.269512 & 4.000000 & 2.149465 & n.o. \\
\hline 10 & Mam (Maya) & 13 & 10 & 0.9615 & 0.0412 & 0.502849 & 0.295539 & 4.525641 & 2.365937 & n.o. \\
\hline 11 & Kiche (Maya) & 16 & 11 & 0.8750 & 0.0810 & 0.486111 & 0.282554 & 4.375000 & 2.269847 & n.o. \\
\hline 12 & Kaqchiquel (Maya) & 13 & 11 & 0.9744 & 0.0389 & 0.658120 & 0.375273 & 5.923077 & 3.005238 & n.o. \\
\hline 13 & Ngöebe & 26 & 10 & 0.8277 & 0.0607 & 0.372308 & 0.219217 & 3.350769 & 1.770379 & n.o. \\
\hline 14 & Kuna & 18 & 6 & 0.7451 & 0.0790 & 0.369644 & 0.221730 & 3.326797 & 1.783639 & n.o. \\
\hline 15 & Wounan & 16 & 9 & 0.9167 & 0.0457 & 0.451852 & 0.265173 & 4.066667 & 2.130050 & n.o. \\
\hline 16 & Embera & 17 & 8 & 0.8529 & 0.0663 & 0.323529 & 0.199000 & 2.911765 & 1.599293 & n.o. \\
\hline 17 & Embera Chamí & 24 & 10 & 0.9022 & 0.0331 & 0.564010 & 0.315135 & 5.076087 & 2.543961 & n.o. \\
\hline 18 & Wayuu & 19 & 18 & 0.9942 & 0.0193 & 0.555556 & 0.314463 & 5.000000 & 2.532312 & n.o. \\
\hline 19 & Bari-Boxi & 16 & 5 & 0.7417 & 0.0727 & 0.351852 & 0.214256 & 3.166667 & 1.720539 & n.o. \\
\hline 20 & Yanomami & 10 & 7 & 0.8667 & 0.1072 & 0.407407 & 0.252607 & 3.666667 & 2.009431 & n.o. \\
\hline 21 & Tiriyo & 35 & 19 & 0.9294 & 0.0284 & 0.458263 & 0.259296 & 4.124370 & 2.098832 & 17.050 \\
\hline 22 & Waiâpi & 13 & 1 & 0.0000 & 0.0000 & 0.0000 & 0.0000 & 0.0000 & 0.0000 & n.o. \\
\hline 23 & Zoe & 25 & 2 & 0.0800 & 0.0722 & 0.008889 & 0.019381 & 0.080000 & 0.156100 & 2.567 \\
\hline 24 & Urubu-Kaapor & 27 & 5 & 0.3390 & 0.1147 & 0.149731 & 0.106399 & 1.347578 & 0.858912 & 5.831 \\
\hline 25 & Awa-Guaja & 46 & 8 & 0.6715 & 0.0664 & 0.167579 & 0.113943 & 1.508213 & 0.923184 & 9.090 \\
\hline 26 & Asurini & 15 & 6 & 0.8476 & 0.0613 & 0.344974 & 0.211664 & 3.104762 & 1.697945 & n.o. \\
\hline 27 & Gavião & 18 & 6 & 0.8301 & 0.0481 & 0.416848 & 0.245600 & 3.751634 & 1.975901 & n.o. \\
\hline 28 & Parakana & 38 & 7 & 0.6174 & 0.0729 & 0.126916 & 0.093363 & 1.142248 & 0.755523 & 4.924 \\
\hline 29 & Ipixuna & 21 & 2 & 0.0952 & 0.0843 & 0.010582 & 0.021411 & 0.095238 & 0.172080 & 0.952 \\
\hline 30 & Kayapo & 16 & 7 & 0.8167 & 0.0729 & 0.452778 & 0.265643 & 4.075000 & 2.133831 & n.o. \\
\hline 31 & Arara & 20 & 4 & 0.6684 & 0.0738 & 0.469591 & 0.270635 & 4.226316 & 2.180365 & n.o. \\
\hline 32 & Cauca-Nariño-Chocó (Colombia) & 31 & 18 & 0.9419 & 0.0252 & 0.486977 & 0.274365 & 4.382796 & 2.219139 & 15.421 \\
\hline 33 & Kichwa Pastaza (Ecuador) & 42 & 21 & 0.9361 & 0.0215 & 0.571429 & 0.313184 & 5.142857 & 2.537772 & 12.804 \\
\hline 34 & Waorani & 39 & 4 & 0.5789 & 0.0550 & 0.369771 & 0.215190 & 3.327935 & 1.742713 & 3.689 \\
\hline 35 & Shipibo-Conibo & 21 & 12 & 0.8524 & 0.0710 & 0.346561 & 0.208319 & 3.119048 & 1.678769 & 15.286 \\
\hline 36 & Peru (pool diversas regiones) & 78 & 70 & 0.9953 & 0.0037 & 0.668887 & 0.356695 & 6.019980 & 2.896786 & n.o. \\
\hline 37 & Junín & 13 & 13 & 1.0000 & 0.0302 & 0.549858 & 0.319712 & 4.948718 & 2.559749 & n.o. \\
\hline 38 & Cuzco & 10 & 8 & 0.9556 & 0.0594 & 0.461728 & 0.281379 & 4.155556 & 2.238815 & n.o. \\
\hline 39 & Arequipa & 16 & 12 & 0.9583 & 0.0363 & 0.525926 & 0.302724 & 4.733333 & 2.432088 & n.o. \\
\hline 40 & Lecos & 11 & 10 & 0.9818 & 0.0463 & 0.612121 & 0.357098 & 5.509091 & 2.849385 & n.o. \\
\hline 41 & Mosetén & 11 & 10 & 0.9818 & 0.0463 & 0.515152 & 0.306503 & 4.636364 & 2.445058 & n.o. \\
\hline 42 & Quechua (Bolivia) & 55 & 39 & 0.9751 & 0.0110 & 0.613244 & 0.331678 & 5.519192 & 2.690738 & n.o. \\
\hline 43 & Aymara (Bolivia) & 59 & 35 & 0.9731 & 0.0096 & 0.561140 & 0.306135 & 5.050263 & 2.484065 & n.o. \\
\hline 44 & Beni & 63 & 35 & 0.9652 & 0.0117 & 0.549297 & 0.300102 & 4.943676 & 2.435624 & 14.958 \\
\hline 45 & Mojeños & 15 & 9 & 0.9048 & 0.0544 & 0.417989 & 0.249056 & 3.761905 & 1.998396 & n.o. \\
\hline 46 & Karitiana & 16 & 4 & 0.5167 & 0.1324 & 0.282407 & 0.178641 & 2.541667 & 1.434140 & n.o. \\
\hline 47 & Terena & 32 & 11 & 0.7883 & 0.0658 & 0.251568 & 0.157617 & 2.264113 & 1.274602 & 12.012 \\
\hline 48 & Colla & 14 & 7 & 0.9011 & 0.0465 & 0.604396 & 0.345670 & 5.439560 & 2.771610 & n.o. \\
\hline 49 & Pilagá & 65 & 29 & 0.9615 & 0.0095 & 0.430502 & 0.242535 & 3.874519 & 1.968469 & 15.496 \\
\hline 50 & Toba & 90 & 41 & 0.9620 & 0.0079 & 0.440089 & 0.246168 & 3.960799 & 1.999678 & 17.167 \\
\hline 51 & Wichi & 45 & 17 & 0.8465 & 0.0433 & 0.342761 & 0.201227 & 3.084848 & 1.630759 & 13.346 \\
\hline 52 & Guaraní & 76 & 20 & 0.8021 & 0.0425 & 0.454659 & 0.253691 & 4.091930 & 2.059967 & n.o. \\
\hline 53 & Rio Grande do Sul & 203 & 157 & 0.9927 & 0.0023 & 0.620072 & 0.330771 & 5.580647 & 2.690271 & n.o. \\
\hline 54 & Mapuche & 49 & 27 & 0.9600 & 0.0125 & 0.537604 & 0.295753 & 4.838435 & 2.398128 & n.o. \\
\hline 55 & Tehuelche & 10 & 10 & 1.0000 & 0.0447 & 0.567901 & 0.337432 & 5.111111 & 2.685747 & n.o. \\
\hline
\end{tabular}

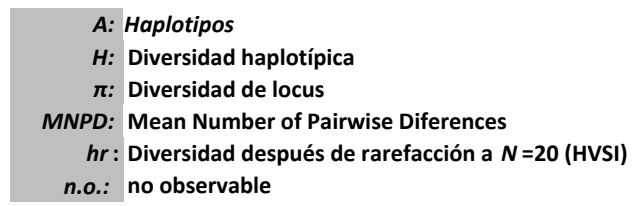

Poblaciones de estudio en negrita

Tabla S4. Indices de diversidad y diversidad genética después de rarefacción a $N=20$ (9-loci) 